This item was submitted to Loughborough's Research Repository by the author.

Items in Figshare are protected by copyright, with all rights reserved, unless otherwise indicated.

\title{
Time-varying role of macroeconomic shocks on house prices in the US and UK: evidence from over 150 years of data
}

\author{
PLEASE CITE THE PUBLISHED VERSION
}

https://doi.org/10.1007/s00181-018-1581-x

\section{PUBLISHER}

(C) Springer

\section{VERSION}

AM (Accepted Manuscript)

\section{PUBLISHER STATEMENT}

This is a post-peer-review, pre-copyedit version of an article published in Empirical Economics. The final authenticated version is available online at: https://doi.org/10.1007/s00181-018-1581-x

\section{LICENCE}

CC BY-NC-ND 4.0

\section{REPOSITORY RECORD}

Plakandaras, Vasilios, Rangan Gupta, Constantinos Katrakilidis, and Mark Wohar. 2018. "Time-varying Role of Macroeconomic Shocks on House Prices in the US and UK: Evidence from over 150 Years of Data". Loughborough University. https://hdl.handle.net/2134/37196. 


\title{
Time-Varying Role of Macroeconomic Shocks on House Prices in the US and UK: Evidence from over 150 Years of Data
}

\author{
Vasilios Plakandaras ${ }^{+*}$, Rangan Gupta ${ }^{* *}$, Constantinos Katrakilidis ${ }^{* * *}$ and Mark E. \\ Wohar ${ }^{* * * *}$ \\ * Department of Economics, Democritus University of Thrace, Greece \\ Email: vplakand@econ.duth.gr \\ ** Department of Economics, University of Pretoria, South Africa. \\ Email: rangan.gupta@up.ac.za \\ *** Department of Economics, Aristotle University of Thessaloniki, Greece \\ Email: katrak@econ.auth.gr \\ ${ }^{* * * *}$ College of Business Administration, University of Nebraska at Omaha, USA; \\ School of Business and Economics, Loughborough University, UK. \\ Email: mwohar@unomaha.edu
}

\begin{abstract}
In this paper, we study the effect of macroeconomic shocks in the determination of house prices. Focusing on the U.S. and the U.K. housing market, we employ timevarying Vector Autoregression models using Bayesian methods covering the periods of 1830-2016 and 1845-2016 respectively. We consider real house prices, output growth, short-term interest rates and inflation as input variables in order to unveil the effect of macroeconomic shocks on house prices. From the examination of the impulse responses of house prices on macroeconomic shocks, we find that technology shocks dominate in the U.S. real estate market, while their effect is unimportant in the U.K. In contrast, monetary policy drives most of the evolution of the U.K. house prices, while transitory house supply shocks are unimportant in either country. These findings are further corroborated with the analysis of conditional volatilities and correlations to macroeconomic shocks. Overall, we are able to unveil the dynamic linkages in the relationship of the macro economy and house prices. Over time, we analyze the variations in economic events happening at the imposition of the shock and uncover characteristics missed in the time-invariant approaches of previous studies.
\end{abstract}

Keywords: time-varying VAR, house prices, macroeconomic shocks

JEL Codes: C32, R30

${ }^{+}$Corresponding author. 


\section{Introduction}

In the aftermath of the Great Recession (2008-2010), considered by the International Monetary Fund as the worst global recession since World War II (International Monetary Fund, 2009), a growing literature attempts to uncover the underlying mechanism that led to this recession (Stock and Watson, 2012; Snowden, 2015). Although the latest 2008 financial crisis has similar characteristics to previous ones (Reinhart and Rogoff, 2009), the usefulness of economic models in forecasting recessions is questioned (Gadea and Perez-Quiros, 2015).

A number of studies emphasize the role of asset price fluctuations, especially house prices, in driving financial and business cycle dynamics (Leamer, 2007; Miller et al., 2011; Balcilar et al., 2014; Nyakabawo et al., 2015; Emirmahmutoglu et al., 2016). Asset price variations affect the real economy as a consequence of the direct effect of households' wealth on consumption (e.g., Iacoviello and Neri, 2010; André et al., 2012; Iacoviello, 2012; Zhou and Carroll, 2012; Case et al. 2013; Liu et al., 2013; Guerrieri and Iacoviello, 2013; Mian et al., 2013; Simo-Kengne et al., 2015). The housing construction sector represents a large part of the total economic activity and consequently reflects a large portion of the total wealth of the economy (Case and Shiller, 2003). Furthermore, forward-looking, rational economic agents incorporate the fluctuations in asset prices in their expectations (Gelain and Lansing, 2014), which, in turn, affects the propagation mechanism of shocks.

While the effect of housing market spillovers onto the real economy, and even onto inflation (Stock and Watson, 2003) has been extensively studied, the link from the real economy to the housing market has attracted less attention. This is true even though the literature on forecasting housing prices have regularly considered the role of many macroeconomic variables (see for example, Gupta et al. (2011) and Plakandaras et al. (2015) for detailed reviews in this regard). What seems to dominate the structural analysis of the housing market is the role of monetary policy (Iacoviello and Minetti, 2003, 2008; Del Negro and Otrok, 2007; Bjørnland and Jacobsen, 2010, 2013; Gupta et al. 2012a, b; Rahal, 2016). The evidence in terms of the importance of monetary policy is mixed. However, this cannot be gauged completely, as other macro shocks affecting the housing market are not explicitly identified. Demary (2010) is an 
exception to this line of research since the study goes beyond monetary policy and identifies three transmission channels between macroeconomic variables and real estate prices based on economic intuition. These channels are i) a contractionary monetary policy leads to an increase in mortgage rates, higher housing costs and lower demand for houses that ultimately lowers house prices; ii) the inflation channel states that an increase in inflation may cause heterogeneous impacts on houses prices. Given that real estate investments can be used to hedge inflation, an increase in inflation encourages residential investment that, in turn, leads to an increase in real estate prices (Demary, 2010). In contrast, the monetary authority is likely to respond to rising inflation by increasing interest rates. This may lead to an increase in housing finance which may lower the demand for real estate and house prices and, iii) a positive shock to output increases the disposable income that can be used to enhance consumption or as investment in real estate. As the economy thrives, the demand for private and professional housing space increases, thus, triggering an increase in construction activities and house prices.

Empirically, Beltratti and Morana (2010) examine the links between macroeconomic variables and the housing market for G-7 countries using a Factor Vector Autoregressive (FVAR) model. The response of the housing industry to macroeconomic shocks indicates that only global-supply side shocks are important determinants of house price fluctuations. Under a similar framework, Del Negro and Otrok (2007) consider a structural VAR model and identify monetary policy shocks by imposing sign restrictions on responses. They find that the impact of policy shocks on the U.S. house prices is rather small in comparison to the response on idiosyncratic shocks. Gattini and Hiebert (2010) examine the long-run relationship between real house prices and real housing investment, real per capita income and real interest rates in the euro area, using a vector error-correction model (VECM). Their empirical findings suggest that real disposable per capita income is important in explaining house price fluctuations in the long run. However, in the short run, it is only housing preferences and specific endogenous factors in the housing market that affect prices.

Assenmacher-Wesche and Gerlach (2008) study a panel dataset comprised of 18 OECD countries and conclude that the impact of monetary policy on house prices is modest. Carstensen et al. (2009) perform a VAR panel regression on the same dataset 
but use different methods to identify structural shocks. In contrast to AssenmacherWesche and Gerlach (2008), they suggest that monetary policy shocks have a large impact on house prices. Nevertheless, as it is explicitly stressed in both studies, there is large uncertainty and cross-country variation in their estimates. Jarocinski and Smets (2008) and Musso et al. (2011) examine country-specific factors for the U.S. and the euro area such as housing construction flexibility, transaction costs, taxes, mortgage market regulation and the proportion of fixed to variable rate mortgages. Their results suggest a modest response of house prices to the aforementioned factors that varies between countries.

Terrones and Otrok (2004) study the dynamics of house prices for 13 industrial countries over the period 1980-2004 using factor models with time-varying construction of the factors based on growth rate, stock prices, per capita output per capita consumption, residential investment and long and short-term interest rate. Their results indicate the significant role of real income growth, interest rates and an autoregressive component in the determination of house prices. Tsatsaronis and Zhu (2004) argue that house prices depend on inflation, the yield curve and bank credit and are more sensitive to short-term rates, since in short-term financing floating mortgage rates and aggressive lending practices are widely used.

Kahn (2008) develops a stochastic Markov-Switching model where the trend of productivity growth explains medium to long-run fluctuations of house prices. Under the specific growth model, short-run price fluctuations are assumed to be the result of a faster growth of housing wealth to private income; thus, this rise inflates and collapses exhibiting a "bubbly" behavior. Focusing on the U.K. housing market, Brooks and Tsolacos (1999) uncover a strong causal relationship between unexpected inflation interest rate term spread and property market. However, the most significant influence on real estate prices originate from idiosyncratic shocks of the real estate market. In a broader examination, Goodhart and Hofmann (2001) implement a fixed-effects panel data model on a sample of 17 industrialized countries over the period 1970-2006 and conclude that short-term interest rates and inflation affect significantly the evolution of house prices in the U.K. In a similar context, Katrakilidis and Trachanas (2013) observe asymmetric long-run effects of inflation and output shocks to Greek house prices depended on the sign of the shock. They conclude that in the short-run house prices 
react immediately to a positive inflation shock, while at longer horizons upward movements in house prices are dominated by downward changes in consumer prices. Overall, the extant literature fails to provide a unanimous answer on the effect macroeconomic shocks to the housing market. The main differences stem from the period under investigation, the methodology used in order to study the shocks and the variables under examination.

Much of the empirical analysis of the housing market assumes a linear relationship between variables with time invariant parameters between macroeconomic fundamentals and housing supply or demand. However, it is reasonable to assume that the linkage between fundamentals and the housing market is not stationary over time and parameters are time varying. One may question the relevance of linear models with time invariant parameters in the analysis of the joint dynamics. Such types of models may not be able to capture the instability of the parameters and uncertainty. Furthermore, the recent empirical literature highlights that macroeconomic and financial variables are affected by structural breaks ${ }^{1}$.

The motivation of this work stems from the limited number of studies on the impact of macroeconomic shocks to house prices and especially to the complete absence of studies using time-varying models. The evolution of the coefficients with time adhere closer to the actual evolution of the phenomenon allowing detailed inference not only for the entire period under examination (as with the constant parameters approach) but also for period-specific observations. Thus, in this paper we examine the relationship between house prices and the macro-economy for the U.S. and the U.K by means of a structural VAR model with time-varying parameters (TVPVAR), spanning the period 1830 to 2016 and 1845 to 2016 respectively. We estimate a time-varying VAR set-up with drifting coefficients and stochastic volatilities. This follows the work of Cogley and Sargent (2005) and Canova and Gambetti (2010). The TVP-VAR model with constant volatility may result in biased estimates. The TVPVAR model with stochastic volatility avoids this misspecification issue by accommodating the simultaneous relations among variables as well as the heteroscedasticity of the innovations. This gain in flexibility comes at the expense of a

\footnotetext{
${ }^{1}$ According to the Bai and Perron structural breaks test, all series exhibit at least one structural break. All results are reported in the Appendix.
} 
more complicated estimation structure. The estimation of the model requires using Markov-Chain Monte-Carlo (MCMC) methods with Bayesian inference.

The use of a time varying model allows the coefficients to evolve over time, adjusting to structural breaks in the dataset such as the Great Depression (1930s), the Great Inflation (1970s), the Great Moderation (1980s through mid-2000s), and the Great Recession (late-2000s). Accordingly, the model allows for possible stochastic volatility in the innovations. More specifically, we examine the response of real house prices to shocks on real output, price level and monetary policy variables, and use the conditional and unconditional evolution of volatility and correlation to uncover possible trends in the housing sector. Instead of assuming exogenous/fixed number of regimes over the entire sample period, as in a Markov-switching model, using the time-varying approach, we consider each point in time as a regime with the transition across them taking place in a smooth rather than abrupt fashion- something we would expect in low frequency (annual) data as in Simo-Kengne $(2015,2016)$.

The relevant literature that examines the relationship of asset prices to macroeconomic variables with the use of TVP-VAR models is limited. Among them are Simo-Kengne et al. (2015) who study the effect of stock and house prices on U.S. consumption, and Koop et al. (2009), Korobilis (2013) and Simo-Kengne et al. (2016) study the time-varying effects of monetary policy on house prices (among other variables).

The innovation introduced by the current analysis is four-fold: a) Unlike most previous studies that consider the role of house price fluctuations in explaining movements in business cycles, and primarily consumption, we focus explicitly on the opposite direction, i.e., the effect of macroeconomic conditions on the real estate market, b) we apply a time-varying approach that adheres more closely to the evolution of the phenomenon that (to the best of our knowledge) has not been applied before in a similar context, c) we study not only monetary shocks to the house prices market but also extend our analysis to other macroeconomic shocks that are not usually included in studying prices response to the housing market and d) we evaluate over a century of data that covers almost the entire economic history and has not been studied before for the U.S. and the U.K. market. More specifically, we build on the previous works that primarily focus on the role of monetary policy on the housing market, and to a very 
limited degree on the importance of other possible macro shocks in driving house prices. More importantly, our analysis is based on unique data sets for the U.S. and U.K. covering over 150 years of data (specifically, 1830-2016 for the U.S. and 18452016 for the U.K.), with results derived from a time-varying framework. These are the longest possible spans of data that can be used related to house prices for these two economies, and hence, allows us to study the evolution of these two countries, and in particular, their respective housing markets in response to various macroeconomic shocks in a time-varying fashion.

In the next sections, we present the basic structure of the TVP-VAR model and the identification method of the structural shocks. Thereafter, our empirical findings and the conclusions based on our findings are discussed.

\section{Methodological issues}

Our work is motivated by Cogley and Sargent (2005) and Canova and Gambetti (2010) who train a TVP-VAR model with Bayesian methods to allow for time-varying VAR coefficients with stochastic volatility on the innovations. We consider a reduced VAR model:

$$
\theta_{t}(L) x_{t}=e_{t}
$$

with $x_{t}=\left\{\Delta y_{t}, \Delta p_{t}, \Delta \mathrm{ir}_{t}, \Delta h p_{t}\right\}$ representing an n-vector of endogenous variables (namely output growth, inflation $(\pi)$, changes in interest rate and real housing returns) at each point of time $t$, each $\theta_{j t}$ in $\theta_{t}(L)=I-\theta_{1 t} L-\cdots-\theta_{1 t} L^{1}$ is a matrix of timevarying coefficients and $e_{t}$ is a vector of zero mean VAR errors with a time-varying covariance matrix $\mathrm{R}_{t}$. The coefficients in (1) evolve according to:

$$
\theta_{t}=\theta_{t-1}+u_{t}
$$

with $\theta_{t}$ denoting the vector that stacks all parameters in $\theta_{t}(L)$ and $u_{t}$ a Gaussian white noise process with zero mean and constant covariance matrix $\mathrm{Q}$, independent of $\varepsilon_{t}$ at all leads and lags. We model the time variations of innovations $\mathrm{R}_{t}=\mathrm{E}\left(e_{t} e_{t}^{\prime}\right)=$ $F_{t} D_{t} F_{t}^{\prime}$, where $F_{t}$ is a lower diagonal matrix with ones in the main diagonal and $D_{t}$ a diagonal matrix. In order to provide flexibility to our model we drop the typical 
homoscedasticity assumption and allow for the existence of stochastic volatility on the VAR errors. In order to achieve this we compute the covariance matrix $\mathrm{R}_{t}$ as follows:

Let's assume that $\gamma_{t}$ is a vector containing all the elements of $F_{t}^{-1}$ below the diagonal, stacked by rows. Then to include stochastic volatility, $\gamma_{t}$ follows (3):

$$
\gamma_{t}=\gamma_{t-1}+\zeta_{t}
$$

In a similar vein, $\sigma_{t}$ is a vector of diagonal elements of $D_{t}$ stacked by rows and follows (4):

$$
\log \sigma_{t}=\log \sigma_{t-1}+\xi_{t}
$$

where $\zeta_{t}$ and $\xi_{t}$ are Gaussian white noise processes with zero mean and (constant) covariance matrices $\Psi$ and $\Xi$, respectively. In order to be able to estimate our model we make a few modest assumptions: a) we assume that $\Psi$ has a block diagonal structure, i.e. all covariances between coefficients belonging to different equations are zero, b) that $\Xi$ is diagonal and c) that $\zeta_{t}, \xi_{t}$ and $u_{t}$ are all mutually independent. Details on the Bayesian estimation of the system are reported in the Appendix.

Following the typical structural shock literature related to monetary VARs with asset prices (see for example, Bjørnland and Leitemo (2009), Bjørnland and Jacobsen, $(2010,2013)$ ), the vector of VAR innovations $e_{t}$ is a (time-varying) linear transformation of the underlying "structural" shocks $\varepsilon_{t}=\left\{\varepsilon_{t}^{y}, \varepsilon_{t}^{\pi}, \varepsilon_{t}^{i r}, \varepsilon_{t}^{h p}\right\}^{\prime}$. The model satisfies $E\left(\varepsilon_{t} \varepsilon_{t}^{\prime}\right)=I$, with $\varepsilon_{t}^{y}$ representing a technological shock, $\varepsilon_{t}^{\pi}$ an inflation (price) shock, $\varepsilon_{t}^{i r}$ the effect of a monetary policy- finance (shock) and $\varepsilon_{t}^{h p}$ a supply/demand shock of the housing market. Thus, $e_{t}=\varphi_{t} \varepsilon_{t}$, where $\varphi_{t}$ is a nonsingular matrix that satisfies $\varphi_{t} \varphi_{t}^{\prime}=R_{t}$. Given this normalization scheme, changes in the contributions of different structural shocks to the volatility of innovations to variables are captured by changes in $\varphi_{t}$. Let the companion form of (1) be:

$$
X_{t}=\Theta_{t} X_{t-1}+H e_{t}
$$

where $X_{t}=\left(x_{t}^{\prime}, x_{t-1}^{\prime}, \ldots, x_{t-l+1}^{\prime}\right)^{\prime}, H=(I, 0, \ldots, 0)^{\prime}$ and $\Theta_{t}$ is the companion-form matrix derived from the autoregressive coefficients of (1). A local projection of (5) 
yields:

$$
\frac{\partial x_{t+k}}{\partial e_{t}}=s_{n, n}\left(\Theta_{t}^{k}\right) \quad \forall t, k=0,1,2, \ldots
$$

where $s_{n, n}(\cdot)$ is the selector function that selects the $n$ rows and columns of a matrix. The application of the chain rule yields the following impulse response at an arbitrary $k$-th horizon:

$$
\frac{\partial x_{t+k}}{\partial \varepsilon_{t}}=\frac{\partial x_{t+k}}{\partial e_{t}} \frac{\partial e_{t}}{\partial \varepsilon_{t}}=s_{n, n}\left(\Theta_{t}^{k}\right) \varphi_{t} \quad \forall t, k=0,1,2, \ldots
$$

We are interested in the identification of level responses and thus of the cumulative responses to each variable. We define $\bar{\Theta}_{t}^{k}=\sum_{j=0}^{k} \Theta_{t}^{j}$ where the level response of each variable to each shock at $\mathrm{k}$ periods is the accumulated response of the differenced series from period zero to period k: $M_{t, k}=\sum_{j=0}^{k} s_{n, n}\left(\Theta_{t}^{j}\right) \varphi_{t}$. From the properties of the selector function we obtain $M_{t, k}=s_{n, n}\left(\bar{\Theta}_{t}^{k}\right) \varphi_{t}$. Letting $k \rightarrow \infty$ defines the time-varying matrix of long-run cumulative multipliers that indicate the long-run effect of each shock on the variable of interest.

Our identification method of structural shocks follows a Blanchard and Quah (1989) type with long-run restrictions on the innovations in order to decompose the responses into permanent and transitory shocks. The identification of the structural shocks is based on well-documented macroeconomic hypotheses. First, according to the long-run neutrality of money approach, an increase or decrease in money supply cannot affect the (real) output. Moreover, according to the natural rate hypothesis, the single source of non-stationarity in real output stems from disturbances to aggregate supply and thus from technological advancements. Thus, we restrict exogenous changes of an inflationary shock to have no long-run effect on output, placing inflation second in the VAR. We also assume that output and inflation react with a lag to monetary policy shocks whereas the monetary policy-maker responds immediately to output and inflation shocks. Thus, the interest rate variable comes third in the ordering of the TVPVAR system. Moreover, given that demand shocks in the housing market are basically transitory shocks uncorrelated to permanent shocks (Gattini and Hiebert, 2010), the 
matrix of cumulative long-run multipliers is a lower triangular matrix. Thus, for the definition of $M_{t, k}$ we use:

$$
M_{t} M_{t}^{\prime}=s_{n, n}\left(\bar{\Theta}_{t}^{\infty}\right) R_{t}\left(s_{n, n}\left(\bar{\Theta}_{t}^{\infty}\right)\right)^{\prime}
$$

with $M_{t}$ obtained from the Cholesky decomposition of (8). Given $M_{t}$ we can solve for $\varphi_{t}$ and obtain the structural impulse responses of each shock according to the ordering $\varepsilon_{t}=\left\{\varepsilon_{t}^{y}, \varepsilon_{t}^{\pi}, \varepsilon_{t}^{i r}, \varepsilon_{t}^{h p}\right\}^{\prime}$

$$
\frac{\partial x_{t+k}}{\partial \varepsilon_{t}}=s_{n, n}\left(\Theta_{t}^{k}\right)\left(s_{n, n}\left(\bar{\Theta}_{t}^{\infty}\right)\right)^{-1} M_{t} \quad \forall t, k=0,1,2, \ldots
$$

Recursive substitution on (7) allows each variable to be written as a timevarying moving representation driven by the underlying structural disturbances. If $x_{i, t}$ represents a distributed lag process for each variable contingent of shock $\mathrm{j}$, we have:

$$
x_{i, t}=\mu_{t}^{i}+\sum_{k=0}^{\infty}\left[\bar{N}_{t, k}\right]_{i, j} \varepsilon_{t-k}^{j}
$$

for $i=\left\{\Delta y_{t}, \Delta \pi_{t}, \Delta \mathrm{ir}_{t}, \Delta h p_{t}\right\}, \varepsilon_{t-k}^{j}=\left\{\varepsilon_{t-k}^{y}, \varepsilon_{t-k}^{\pi}, \varepsilon_{t-k}^{i r}, \varepsilon_{t-k}^{h p}\right\}$ and $\bar{N}_{t, k}=s_{n, n}\left(\Theta_{t}^{k}\right)$. From (10) we see that the time-varying unconditional variance of $x_{i, t}$ is decomposed into the contribution of each shock to the variance of each variable according to the following:

$$
\operatorname{var}_{t}\left(x_{i, t}\right)=\sum_{k=0}^{\infty}\left[s_{n, n}\left(\Theta_{t}^{k}\right) \varphi_{t}\right]_{i, j}^{2}
$$

and the time varying covariance of $x_{i, t}$ and $x_{q, t}$ conditional on each shock $\mathrm{j}$ is given by:

$$
\operatorname{covar}_{t}\left(x_{i, t}, x_{q, t}\right)=\sum_{k=0}^{\infty}\left[s_{n, n}\left(\Theta_{t}^{k}\right) \theta_{t}(1) M_{t}\right]_{i, j}\left[s_{n, n}\left(\Theta_{t}^{k}\right) \theta_{t}(1) M_{t}\right]_{q, j}
$$

Time-varying unconditional and conditional correlations are given tractably from (11) and (12). 


\section{Data and Empirical Results}

\subsection{The Data}

We compile a dataset of annual time series for the U.S. and U.K. spanning the periods of 1830-2016 and 1845-2016 respectively, which includes real Gross Domestic Product $(y)$, Consumer Price Index $(p)$, nominal short term interest rate (ir), and real house prices $(h p)$, with the latter obtained by deflating the nominal house prices with the consumer price index. All variables for the U.S. were sourced from the Global Financial Database. While data for the U.K. is derived from the database called the Three Centuries of Data (Version 2.3), maintained by the Bank of England ${ }^{2}$. An advantage of using a relatively long sample is the ability to examine how economies, and especially the housing market of these two countries, have evolved over time covering almost their entire modern economic history. All data except interest rates are transformed into logarithms. Conventional unit root tests fail to reject the existence of unit roots for all variables in levels, but not in first differences. ${ }^{3}$ Hence, we work with growth rate of output, inflation, changes in interest rate and real housing returns, as indicated by: $\Delta y_{t}, \Delta p_{t}, \Delta \mathrm{ir}_{t}, \Delta h p_{t}$, respectively.

\subsection{Empirical findings}

We train a TVP-VAR model and estimate the conditional and unconditional deviations and correlations as well as the Impulse Responses of a shock on output, inflation and interest rate on house prices. Given the time-varying nature of the model there is no need to test for the existence of structural breaks (Korobilis, 2013). We choose a lag length of two based on the SIC criterion applied to a VAR with constant parameters over time.

In Figure 1, we report the coefficients for the house prices (fourth) equation. Given the time-varying nature of our model and the Bayesian estimation that provides

\footnotetext{
2 http://www.bankofengland.co.uk/research/Pages/datasets/default.aspx

${ }^{3}$ We use standard unit-root tests: Augmented-Dickey-Fuller (ADF)(1981), Phillips-Perron (PP) (1988), Dickey-Fuller with Generalised-Least-Squares-detrending (DF-GLS) (Elliott et al. , 1996), and the NgPerron modified version of the PP (NP-MZt) (2001) tests to confirm that the (log-)levels of the variables under consideration follow an integrated process of order 1 or are I(1) processes. All unit root tests are available from the authors upon request.
} 
the entire posterior distribution of the coefficients, we report both posterior median values and $68 \%$ intervals instead of the typical t-test and F-test statistics. ${ }^{4}$

As we observe from figure 1, the time-varying coefficients of the first lag for output are mostly statistically insignificant, while the parameters for the second lag are significant in the post-1960 period $^{5}$. In fact, output coefficients exhibit the highest effect on house prices with the maximum value of the median value reaching 2 . In other words, a unit increase in output increases houses prices after 2 years by two units. In contrast, inflation parameters are statistically significant for both lags, but the negative values in the median value of the first lag are mostly compensated in half by the positive values of the second lag. Thus, inflation appears to have a small positive effect on house prices. The median values of the interest rate coefficients for the first lag are negative and slightly declining with a value around -0.5 , while the second lag has statistically significant coefficients in the post 1960 period and stabilizes around -2 on the Great Moderation period and onwards. This finding is expected and is consistent with the literature, because an increase of the interest rate deteriorates financing of construction investments. This negative relationship is at a maximum in the Volcker administration period, where the focus of monetary policy shifted from growth to restraining inflation. The coefficients of house prices are almost all statistically insignificant. Overall, the key drivers in the evolution of U.S. house prices appear to be the lagged values of output and interest rates, with an almost symmetric and opposite effect.

The situation is different for the U.K. Results reported for the UK in Figure 2 show that both the output growth and inflation coefficients are statistically insignificant in both lags. This finding is strikingly different from the extant literature, since earlier studies detect a predominance of inflation shocks in the housing market (Tsatsaronis and Zhu, 2004). The difference in our empirical findings could be attributed to the timevarying nature of our model that allows for the detection of "local" trends in the sample. Earlier studies based on the constant parameter SVAR model failed to capture this feature since it is commonly smoothed out in long-span datasets. The interest rate coefficients have the right sign and indicate that the monetary policy is the main driver

\footnotetext{
${ }^{4}$ Estimates for output growth, inflation and interest rate equations are reported in the Appendix.

${ }^{5}$ Following the typical inference procedure of confidence intervals for VAR models, when zero is included in the confidence intervals then the impact of this variable is named "insignificant" as its coefficient does not differ from zero with statistical significance.
} 
of evolution of house prices. Moreover, the coefficients of the first lag of house prices are statistically significant and larger than the other coefficients through time, implying a persistence of house price, consistent with arguments in Terrones and Otrok (2004). Thus, U.K. prices emerge to be more persistent than U.S. house prices, while monetary policy is of key importance to both real estate markets.

\subsubsection{Impulse Response analysis}

Although the analysis of the time-varying coefficients provides valuable information on the existence of a causal relationship among house prices and fundamentals, it lacks the perspective of a time evolution of structural shock - an assessment of the response of the housing market to a change in fundamentals over time. In this vein, we examine the time-varying response of house prices to a structural shock in fundamentals, permanent or transitory. The permanent shocks on output, inflation and interest rate are coded as "technological shock", "price shock" and "financial (money) shock", respectively. As in Demary (2010), the aforementioned shocks are allowed to have a permanent effect on house prices, while supply and demand fluctuations in the housing market have only a transitory shock on house prices. As in Matsyama (1999) we treat all changes in the regulatory framework as a technology shock. For instance, an increase or decrease in the time required to obtain a building permit, changes in the various zoning laws, changes in the tax system that might encourage or discourage home ownership, shifts in demographics and availability of land can affect the housing market.

In figures 3 and 4, we report the impulse response functions (IRF) for the U.S. and the U.K real estate market, respectively. Given the time-varying nature of our model, we have to add one more axis to the IRF plots that corresponds to the date of the imposition of the shock. As it is obvious from the IRFs, all shocks are short-lived up to approximately 5 years ahead and have zero effect beyond that point. Given the inability to plot confidence intervals in the two plots (as the figures would become unreadable), we splice 2D graphs for each IRF for 1, 2, 3 and 5 years ahead, depicted in figures 5 and 6 for the U.S. and the UK respectively.

A technology shock (figure 5, subplots a-d) has a positive, significant and persistent impact in the long run on U.S. house prices, consistent with theory. Given the dual nature of the housing market as a consumption as well as an investment asset 
(Leung, 2004), a positive technology shock increases disposable income, shifting consumption up and eventually encouraging investment on the housing market. The response to a technology shock is realized within a two-year lag length that is consistent with the actual experience, given the time limitations in funding and completing a housing construction project. The response of house prices is found to be higher before WWII and smaller in the period after the Great Moderation (1984-2007), exhibiting two peaks around the 1900s and the 1930s; the period of the 1907 Panic and the Great Depression. This finding is interesting since it corroborates with the business cycle literature that supports the existence of high macroeconomic volatility during periods of increased macroeconomic uncertainty.

In contrast to the response of house prices to a technology shock, the response to an inflation shock (subplots e-h) is short-lived. In the first year (subplot e), the response is statistically significant before the Great Depression and during the WWII period. However, on the second year, after the imposition of the shock (subplot $f$ ) the response turns negative and significantly smaller in absolute terms. From that point and onwards, no response is statistically significant. The small negative response of house prices to a price shock follows the monetary literature, which states that an increase in inflation forces the monetary authority to react by increasing interest rates and reducing investments in the housing construction sector, aiming at the stabilization of prices (Demary, 2010; Katrakilidis and Trachanas, 2013). These findings corroborate with our previous results of the TVP-VAR coefficients regarding inflation and pinpoint the effectiveness of the inflation-targeted policies of the Federal Reserve on the stabilization of asset prices (Simo-Kengne et al., 2015).

Under a similar perspective, a money shock (figure 5, subplots i-1) induces a negative effect on house prices, since an increase of interest rates drives house prices downwards due to higher mortgage rates and lower demand in the real asset market. In terms of magnitude, the monetary policy effect is higher in the post 1970s period. Interestingly, the response of house prices to transitory idiosyncratic shocks of the housing market (subplots $m-p$ ) is very small, positive and statistically significant only on the second year (subplot n) and only to the pre 1970s period. Given the economic changes following the Great Depression and the WWII period, these transitory shocks 
in house demands have no long-run effect to the house prices and could be attributed to supply shocks in the housing market.

Overall, our results corroborate with the literature on the significance of technology shocks in the long run (Kahn, 2008; Gattini and Hiebert, 2010) and the negative effect between money shocks and house prices (Demary, 2010). However, we do not find a significant autoregressive effect of house prices in line with Del Negro and Otrok (2007), Gattini and Hiebert (2010) and Terrones and Otrok (2004). This difference could be attributed to our time-varying approach and the different identification scheme that we use, which makes it possible to unveil local trends in the house prices that are typically smoothed out in time-invariant approaches with longspan data sets used in the majority of the previous studies.

Regarding the U.K. housing market depicted in figure 6, the response of house prices on technology, money and idiosyncratic house prices shocks is qualitatively similar to that of the U.S. market. In fact, the technology shocks appear to have a positive effect earlier than in the U.S. market from the third year (figure 6, subplot c) after the imposition of the shock and retain their significance up to the fifth year (subplot d). The effect of technology shocks on house prices is stronger and more persistent in the case of the U.K. The long-term effect of the money shock (figure 6, subplot $\mathrm{h}$ ) is positive, significant and higher than the corresponding U.S. effect (figure 5 , subplot $\mathrm{h}$ ), implying a tighter supervision of the housing market by the monetary authority. Interestingly, price shocks (subplot 1) have a significant positive effect on house prices in the long run, in line with the notion that house assets could be used to hedge inflation (Demary, 2010; Brooks and Tsolacos, 1999).

This fact is not observable in the U.S. market and probably stems from the different characteristics of the U.K. housing market. Overall, our analysis lead to the emergence of several interesting differences between the responses of the U.S. and the U.K. housing market. Due to land limitations in the U.K., the housing supply is smaller than that of the vast U.S. housing market, assuring higher prices and smaller price fluctuations. Higher prices drive U.K. households to invest earlier and for more years in a residence than a corresponding U.S. household (Bouchouicha and Ftiti, 2012). This wealth effect can be observed in the large U.K. cities. Thus, investment in U.K. housing 
is used to hedge inflation, which is not the case in the U.S. market. This finding is obvious from figures 5 (subplot $\mathrm{h}$ ) and 6 (subplot $\mathrm{h}$ ), where the long-term response on a money shock is positive, significant and higher than the corresponding U.S. effect, while price shocks (subplot 1) have a significant positive effect on house prices in the long run only for the U.K. market.

\subsubsection{Volatility and Correlation}

In the extant literature on macroeconomic research, a pivotal point is the effect of the fiscal and monetary policy on the volatility of economic macroeconomic fundamentals. In the finance literature, the historical risk when investing in an asset is assumed to be its historical volatility. Hence, in the boundaries of this paper, the evolution of house price volatility could provide valuable information on the evolution of the real estate market conditioned on macroeconomic shocks. Given the time-varying nature of our approach, we are able to examine the time evolution of both the conditional and the unconditional house prices volatility on each type of shock. In figure 7, we report the conditional and unconditional standard deviations from the response of U.S house prices to the three permanent macroeconomic shocks. ${ }^{6}$

As we observe, the (unconditional) volatility of house prices for the U.S. rises significantly in the pre-1945 period with significant spikes during the banking Panic of 1907, the period of the Great Depression and the early years after the end of WWII. The volatility drops significantly during the 1960s and 1970s and bottoms out during the period of the Great Moderation. Beyond that point, it increases again with the boom of the housing market in the 2000s and falls in the Great Recession period, eroding almost all the gain in the stabilization of prices achieved during the Great Moderation period. As reported in figure 7, most of these price fluctuations were sparked by significant economic events and changes in policy (and so the term "Great"). The most significant components of volatility are transitory demand shocks in the market. In contrast, money shocks exhibit two significant spikes during the Great Depression period and the 1960s. After these periods, the contribution of the conditional volatility

\footnotetext{
${ }^{6}$ We examine standard deviations instead of variances, since house prices are expressed in U.S dollars and British Pounds, respectively. Thus, variances would have no physical meaning.
} 
of the money shock is small and probably insignificant, implying a small effect of monetary policy on the U.S. housing market.

The technological shock (output) is the second most important (permanent) factor, with its contribution peaking during the Great Depression and the Great Moderation periods. During the Great Depression period, a decrease in output led to an increase in house price volatility, as a result of high macroeconomic uncertainty. During periods of high macroeconomic uncertainty, downward movements in investment and in disposable income affect asset prices negatively. In contrast, during the Great Moderation period, the inflation targeted policies of the Federal Reserve achieved a stabilization of prices. Moreover, technological innovations introduced in the housing construction industry after the 1970 s reduced construction costs. These factors led to a decrease in the fluctuation of house prices.

Table 1 summarizes our main conclusions from figure 7 in a quantitative manner. It reports posterior standard deviations of TVP-VAR estimates at key points in time and facilitates a numerical comparison of house price volatility between different time periods. The difference in the volatility between two consecutive periods is measured as the percentage decline in standard deviation from the local peak in the period and the local trough. Given the Bayesian nature of the model, we compute the lower bound for each peak and the upper bound for each trough on the 16th to 84th intervals. When the lower bound on the preceding peak exceeds the upper bound on the following trough, we interpret that as evidence of a statistically significant reduction in the standard deviation since the confidence bounds associated with peak and trough do not overlap one another. ${ }^{7}$

We find a statistically significant drop in house price volatility between 19451971 and 1971-1984 conditioned on macroeconomic shocks, with the largest reduction noticeable for the technology and money shocks. We also observe some sporadic events of change in volatility for the other periods. What is interesting is that while we observe a significant increase in post-war volatility conditioned on the technology shocks, the changes in volatility of the Great Moderation and after period are statistically non-

\footnotetext{
${ }^{7}$ In the Appendix we report in detail the standard deviation for all local extrema, along with the year in which those extrema occurred and the lower and upper bounds for all troughs and peaks.
} 
existent for all fundamentals' shocks. This finding implies that despite the 2008 financial crisis the volatility of house prices has remained similar, suggesting small changes in the structure of the market and its dynamic relationship with the macroeconomy.

The posterior estimates of conditional and unconditional correlations of macro shocks with house prices (along with the confidence intervals) are shown in figure 8 . We depict the conditional to macro shocks correlations of output growth to house prices in subplots (a) to (c) and the corresponding unconditional correlation to subplot (d). While subplots (a) and (b) reveal statistically insignificant correlations, we detect a positive and significant correlation near unity when we condition the correlation on money shocks (subplot c). If we combine the findings from figures 7 and 8 , we argue that money shocks drive volatility and correlation during the period spanning the Great Depression until WWII. The unconditional correlation (subplot d) is close to zero, implying that the effect of money shocks is dampened by the opposite and quantitatively similar combined effect of prices and technology shocks over time.

In subplots (e) to (h), we depict the conditional and unconditional correlations among house prices and inflation. As we observe, conditioned on the technology (subplot e) and the money shock (subplot $\mathrm{f}$ ) there is a negative correlation between inflation and house prices that is statistically significant in the post 1970s period. Inflation targeted policies in the post-Great Moderation period stabilized prices, while interest rate changes (money shocks) became the main policy instrument driving the economy. Especially for house prices, a lowering inflation rate in the post-1984 period constitutes the main reason for the small correlation with output (conditioned on the technological shocks- subplot e), while also reflects the importance of money shocks in shaping preferences of real estate investors. Interestingly, the correlations of house prices to interest rates shown in subplots (i) to $(\mathrm{k})$ reveal no statistically significant relationship after 1984. This finding suggests that although the money shock does not affected house prices directly (as we also infer from the analysis of the IRFs), it can affect house prices correlation indirectly through changes in output growth and inflation, a pattern that is obvious due to our time-varying coefficients and missed by earlier studies (Musso et al., 2011). 
In figure 9, we report the conditional and unconditional volatilities for the U.K. house prices. As we observe, throughout time, price volatility is smaller than the corresponding U.S. values. The unconditional deviation exhibits two significant peaks; a) during the 1920s period and the post WWII economic recession and b) during the period 1970-1980, an era of general economic and social turbulence in the U.K. Especially in the period 1970-1980 the U.K. economy exhibited a supply (technological) shock that increased the volatility of most macroeconomic variables. Interestingly, the period with the lowest variability is the post Great Recession period presumably due to the quantitative easing program of the Bank of England that stabilized the economy and the small but positive output growth rates. A close examination of figure 9 reveals that the conditional volatility on monetary policy shocks follow almost identically the fluctuations of the unconditional volatility (we return to this observation in more detail later when we examine the conditional and unconditional correlations).

The effect of a transitory housing market shock accounts for the largest part of volatility until the 1970s and falls significantly thereafter, pointing to structural changes to the economy that produced the earlier fluctuations in house prices. The technology shock has the lowest contribution in all periods apart from the period 1970-1985. Thus, price volatility can be attributed to price and money shocks. Especially in the period after the 1984, the effect of the technology shock is small and declining. Most of the variation in the post-2008 period stems from transitory and inflation-monetary policy shocks with a declining trend.

In Table 2, we summarize the volatility fluctuation differences over different time periods. In order to keep our results comparable with those of the U.S. market, we keep the same time splits. Despite the existence of large percentage changes in volatility, only three changes are statistically significant, presumably due to smaller volatility values in comparison to the U.S. The only interesting finding is the reduction in volatility between the pre and post 1984 period. These fluctuations in volatility could be attributed to a supply increase in the post 1984 period in the housing market (transitory shock) and the volatility of the English economy during the 1970-1980 period that affects the output growth rate (technology shock). 
Our analysis of the time-varying correlation of house prices with macroeconomic variables (figure 10) reveals some interesting facts. Conditioned on price shocks, the correlation between output growth rate and house prices becomes high and significant for the period 1950-1980 (subplot b), about the same period where price volatility spikes. Given the high inflation during that period (surpassing 20\% at 1975), this finding reveals the important role of inflation on the investing decisions on the U.K. real estate market. Secondly, conditioning on money shocks (subplot c), the correlation becomes high and significant. Again, this is an indication that monetary policy drives the co-movement between output growth and house prices as an instrument to hedge inflation. The (combined) unconditional correlation shown in subplot (d) is zero for almost the entire sample, with a small exception over 1980s, a period of considerable volatility on all economic sectors.

In subplots (e) - (h) we report the correlation of inflation to house prices. The significant negative correlation conditioned on technology shocks during the period 1960-1990 (subplot e) implies that investment on housing can hedge inflation-boosting growth. This effect is also obvious for the money shock (subplot $\mathrm{f}$ ). The unconditional correlation is again insignificant (subplot h). In subplots (i) to (k) we focus on the conditional correlation among interest rates and house prices. Apparently, the high and statistically significant correlation between monetary policy and housing prices conditioned on the money shock (subplot k) and the unconditional correlation (subplot 1) after the $1960 \mathrm{~s}$, reveals the significant role of interest rates to house prices.

Overall, from the analysis of impulse responses, conditional and unconditional volatility and correlations we conclude that monetary policy are an important determinate of house prices in the U.K. Although this finding is not new to literature (Brooks and Tsolacos, 1999), our time-varying examination provides new insight into period dependent inferences on the evolution of house prices conditioned on monetary policy shocks.

\subsubsection{VAR with time-invariant coefficients}

As already pointed several times in this paper, most of the empirical literature exploits models with time-invariant coefficients. In order to compare our work to previous studies, we train a time-invariant $\operatorname{VAR}(2)$ model and estimate impulse 
responses of house prices to macroeconomic shocks. ${ }^{8}$ All responses for the U.S. market are shown in figure 11. They are constructed based on the identification scheme of longrun restrictions also used on the TVP-VAR model.

All responses of house prices are small and statistically insignificant from zero, with the exception of the transitory house prices shock that exhibits a positive but shortlived effect. Thus, the use of constant coefficients as in Musso et al. (2011) and Del Negro and Otrok (2007) overstates the transitory effect of supply/demand shocks in the housing market and is not able to uncover time-varying phenomena based on the actual economic conditions on each point in time, since they are smoothed-out during the estimation of the VAR model.

In figure 12, we report the corresponding IRFs for the U.K. market. The results are quantitatively similar to the U.S. market, rendering the constant coefficient analysis not suitable for our cause.

\section{Conclusions}

In this paper, we study the dynamic relationship of the U.S. and the U.K. housing market with the macroeconomy, focusing on the effect of macroeconomic shocks on the evolution of house prices. In the process, we build a time-varying VAR model over the periods of 1830 to 2016 and 1846-2016 for the U.S. and U.K. respectively, by including real house prices, output growth, real central bank interest rates and inflation incorporating stochastic volatility. We examine the dynamic evolution of the coefficients of the models, the impulse responses of house prices on the macroeconomic shocks and the conditional and unconditional volatility and correlation of house prices to fundamentals.

Regarding the U.S. housing market, our empirical findings corroborate to previous literature on the importance of technology shocks on house prices and the existence of a small and negative relationship between monetary policy and the housing sector. However, we reject the importance of transitory supply shocks of the housing

\footnotetext{
${ }^{8}$ All inverse roots of the AR characteristic polynomial lie inside the unit circle, thus the system is stable. Detailed characteristics of the VAR models are not reported here due to space limitations; they are considered typical in the literature and are not relevant to our analysis. They are available from the authors upon request.
} 
market on house prices, reported in earlier studies. This divergence can be attributed to the time-varying nature of our approach that associates each shock with the specific economic conditions that prevail over the time of its imposition.

The empirical findings on the U.K. housing market emphasize on the importance of monetary policy on the housing sector, with the effect of the technological shocks on house prices being unimportant. Overall, the time-varying character of our approach adhere to the main economic phenomena that drive house price, describe adequately the contribution of each macroeconomic variable and provide a deep understanding on the dynamic relationship of the housing market and the economy.

In sum, from a policy perspective, with monetary policy being the only policyrelated variable in the system, we can conclude that, historically monetary policy shocks have been of less importance in the U.S. than in the U.K. in driving their respective housing markets. To put it alternatively, bubbles in the housing market in the U.S. cannot be attributed to loose monetary policy, but indeed in the U.K., expansionary monetary policy can causes possible bubbles. At the same time, tighter monetary policy in the U.K., can ensure that there are no bubbles in the housing market, but the same cannot be said so about the U.S. housing market. However, it must be realized that to detect the bubbles, there needs to be real-time housing market monitoring technology in the first place. For the U.S., technological developments are much more of importance relative to the U.K., so the monetary authorities needs to be careful that excessive technological developments does not necessarily over-heat the market by pursuing contractionary monetary policy to control the market as far as possible, keeping in mind that this could possibly involve large interest rate hikes, given the limited impact of monetary policy on the U.S. housing market. Though not analysed in this paper, perhaps for the U.S., to control for possible bubbles, one would need intervention from the fiscal side (El Montasser et al., forthcoming).

\section{Compliance with Ethical Standards:}


This study was not financially supported. All authors declare that they have no a conflict of interest. This article does not contain any studies with human participants or animals performed by any of the authors.

\section{Acknowledgments:}

We would like to thank the editor and two anonymous reviewers for their insightful comments that improved substantially our paper. Any remaining errors are our own responsibility. 


\section{References}

André, C., Gupta, R., and Kanda, P.T. (2012). Do house prices impact consumption and interest rate? Evidence from OECD countries using an agnostic identification procedure, Applied Economics Quarterly, 58 (1), 19-70.

Assenmacher-Wesche, K. and Gerlach S. (2008). Ensuring financial stability: financial structure and the impact of monetary policy on asset prices. Iew - working papers, Institute for Empirical Research in Economics - University of Zurich, No. 361.

Balcilar, M., Gupta, R., and Miller, S.M. (2014). Housing and the great depression. Applied Economics, 46(24), 2966-2981.

Beltratti, A. and C. Morana (2010). International house prices and macroeconomic fluctuations. Journal of Banking and Finance, 34, 533-545.

Bjørnland, H. and Jacobsen D. (2010). The role of house prices in the monetary policy transmission mechanism in small open economies. Journal of Financial Stability, $6(4), 218-229$.

Bjørnland, H. and Jacobsen D. (2013). House prices and stock prices: Different roles in the U.S. monetary transmission mechanism. Scandinavian Journal of Economics, 115 (4), 1084-1106.

Bjørnland, H. and Leitemo, K. (2009). Identifying the interdependence between US monetary policy and the stock market. Journal of Monetary Economics, 56, 275282.

Blanchard, O.J. and Quah, D. (1989). The dynamic effects of aggregate demand and supply disturbances. American Economic Review, 79 (4), 655-673.

Bouchouicha, R. and Ftiti Z. (2012). Real estate markets and the macroeconomy: A dynamic coherence framework. Economic Modelling, 29, 1820-1829.

Brooks, C. and Tsolacos S. (1999). The Impact of economic and financial factors on UK property performance. Journal of Property Research, 16 (2), 139-152.

Canova F. and Gambetti, L. (2010). Do expectations matter? The great moderation revisited. American Economic Journal: Macroeconomics, 2 (3), 183-205.

Carstensen, K., Hulsewig, O. and Wollmershaauser, T. (2009) Monetary policy transmission and house prices: European cross-country evidence. Working paper 7, European Commission.

Case, K., Quigley, J., and Shiller, R., (2013). Wealth effects revisited: 1975-2012. NBER Working Paper No. 18667.

Case, K.E. and Shiller, R.J., (2003) Is there a bubble in the housing market? Brookings Papers on Economic Activity, 2.

Cogley, T. and Sargent, T. (2005). Drifts and volatilities: monetary policies and outcomes in the post WWII US. Review of Economic Dynamics, 8 (2), 262-302.

Del Negro, M. and C. Otrok. (2007). 99 Luftballons: Monetary policy and the house price boom across U.S. States. Journal of Monetary Economics, 54, 1962-1985.

Demary, M., (2010). The interplay between output, inflation, interest rates and house prices. International evidence Journal of Property Research, 27 (1), 1-17.

Dickey, D. and Fuller, W. (1981). Likelihood ratio statistics for autoregressive time series with a unit root. Econometrica, 49, 1057-1072. 
El Montasser, G., Gupta, R., Jooste, C., and Miller, S.M. (Forthcoming). The timeseries linkages between U.S. fiscal policy and asset prices. Public Finance Review.

Elliott G., Rothenberg T. and Stock J. (1996). Efficient tests for an autoregressive unit root. Econometrica. 64 (4), 813-836.

Emirmahmutoglu, F., Balcilar, M., Apergis, N., Simo-Kengne, B.D., Chang, T., and Gupta, R. (2016). Causal relationship between asset prices and output in the US: Evidence from state-level panel Granger causality test. Regional Studies, 50 (10), 1728-1741.

Gadea, M.D. and Perez-Quiros G. (2015). The failure to predict the Great Recession. A view through the role of credit. Journal of the European Economic Association, 13, 534-559.

Gattini, I. and P. Hiebert (2010). Forecasting and assessing euro area house prices through the lens of key fundamentals. ECB Working Paper, No. 1249.

Gelain, P. and Lansing, K.J. (2014). House prices, expectations and time-varying fundamentals. Journal of Empirical Finance, 29, 3-25.

Goodhart, C. and Hofmann, B. (2001). Asset prices, financial conditions and the transmission of monetary policy. Conference on Asset Prices, Exchange Rates, and Monetary Policy, Stanford University.

Guerrieri, L. and Iacoviello, M. (2013). Collateral constraints and macroeconomic asymmetries. Journal of Monetary Economics, 90, 28-49.

Gupta, R., Jurgilas, M., Kabundi, A., and Miller, S.M. (2012a). Monetary policy and housing sector dynamics in a large-scale Bayesian vector autoregressive model. International Journal of Strategic Property Management, 16(1), 1-20.

Gupta, R and Kabundi, A. and Miller, S.M. (2011) Forecasting the US real house price index: structural and non-structural models with and without fundamentals. Economic Modelling, 28, 2013-2021.

Gupta, R., Miller, S.M., and van Wyk, D. (2012b). Financial market liberalization, monetary policy, and housing price dynamics. International Business \& Economics Research Journal. 11 (1), 69-82

Iacoviello, M. (2012). Housing Wealth and Consumption. International Encyclopedia of Housing and Home, 673-678, Elsevier.

Iacoviello, M., and Minetti, R. (2003), Financial liberalisation and the sensitivity of house prices to monetary policy: Theory and evidence. The Manchester School, 71 (1), 20-34.

Iacoviello, M., and Minetti, R. (2008). The credit channel of monetary policy: evidence from the housing market. Journal of Macroeconomics, 30 (1), 69-96.

Iacoviello, M., and Neri, S. (2010). Housing market spillovers: Evidence from an estimated DSGE model. American Economic Journal: Macroeconomics, 2, 125164.

International Monetary Fund (2009). World Economic Outlook (April).

Jarocinski M. and Smets F. (2008). House prices and the stance of monetary policy. Federal Reserve Bank of St. Louis Review, 339-370.

Katrakilidis, K. and Trachanas, E. (2013) What drives housing price dynamics in Greece: New evidence from asymmetric ARDL cointegration. Economic Modelling, 29, 1064-1069. 
Kahn, J. (2008) What drives housing prices? Federal Reserve Bank of New York Staff Reports, no. 345.

Koop, G., Leon-Gonzalez, R. and Strachan, R.W. (2009). On the evolution of the monetary policy transmission mechanism. Journal of Economic Dynamics and Control, 33, 997-1017.

Korobilis, B. (2013) Hierarchical shrinkage priors for dynamic regressions with many predictors. International Journal of Forecasting, 29, 43-59.

Leamer, E.E. (2007). Housing is the business cycle. NBER Working Paper No. 13428.

Leung, C (2004) Macroeconomics and housing: a review of the literature. Journal of Housing Economics 13 (4):249-267.

Leung, C. (2004). Macroeconomics and housing: a review of the literature. Journal of Housing Economics, 13(4), 249-267.

Liu, Z., Wang, P., and Zha, T. (2013). Land-price dynamics and macroeconomic fluctuations. Econometrica, 81, 1147-1184.

Matsuyama, K. (1999). Residential investment and the current account. Journal of International Economics, 28 (1-2), 137-153.

Mian, A. R., Rao, K., and Sufi, A. (2013). Household balance sheets, consumption, and the economic slump. The Quarterly Journal of Economics, 128 (4), 1687-1726.

Miller, N., Peng L., and Sklarz, M., 2011. House prices and economic growth. Journal of Real Estate Finance and Economics, 42 (4), 522-541.

Musso, A., Neri S., and Stracca L. (2011). Housing, consumption and monetary policy: How different are the US and the euro area? Journal of Banking \& Finance, 35 (11), 3019-3041.

Ng, S. and Perron, P. (2001). Lag length selection and the construction of unit root tests with good size and power. Econometrica, 69, 1519-1554.

Nyakabawo, W., Miller, S.M., Balcilar, M., Das, S., and Gupta, R. (2015). Temporal causality between house prices and output in the U.S.: A bootstrap rolling-window approach. North American Journal of Economics and Finance, 33 (1), 55-73.

Phillips, P. and Perron, P. (1988). Testing for a unit root in time series regression. Biometrika, 75, 335-346.

Plakandaras, V., Gupta R., Gogas P. and Papadimitriou T. (2015). Forecasting the U.S. real house price index. Economic Modelling, 45, 259-267.

Rahal, C. (2016). Housing markets and unconventional monetary policy. Journal of Housing Economics, 32, 67-80.

Reinhart, C.-M. and Rogoff K. (2009). This Time Is Different: Eight Centuries of Financial Folly. Princeton, New Jersey: Princeton University.

Simo-Kengne, B.D., Miller, S., Gupta, R. and Aye, C. (2015) Time-varying effects of housing and stock returns on U.S. consumption. Journal of Real Estate Finance and Economics, 50, 339-354.

Simo-Kengne, B.D., Miller, S.M., Gupta, R., and Balcilar, M. (2016). Evolution of the monetary transmission mechanism in the US: The role of asset returns. The Journal of Real Estate Finance and Economics, 52 (3), 226-243.

Snowden N. (2015) What really caused the Great Recession? Rhyme and repetition in a theme from the 1930s. Cambridge Journal of Economics, 39 (1), 1245-1262. 
Stock, J.H. and Watson, M.W. (2003). Forecasting output and inflation: The role of asset prices. Journal of Economic Literature, XLI, 788-829.

Stock, J.H. and Watson, M.W. (2012). Disentangling the Channels of the 2007-2009 Recession. NBER Working Paper, No. 18094

Terrones, M. and Otrok, C. (2004). The global house price boom, World Economic Outlook, 71-89.

Tsatsaronis, K. and Zhu, H. (2004). What drives housing price dynamics: cross-country evidence. Bank of International Settlements Quarterly Review (March), 65-78.

Zhou, X. and Carroll, C. D. (2012). Dynamics of wealth and consumption: new and improved measures for U.S. states. The B.E. Journal of Macroeconomics, 12, 144. 
Table 1: Changes in volatility over different time periods for U.S. house prices

\begin{tabular}{l|c|c|c|c|c}
\hline & $\begin{array}{c}1880-1930 \\
\text { vs 1930- } \\
1945\end{array}$ & $\begin{array}{c}1930-1945 \\
\text { vs 1945- } \\
1971\end{array}$ & $\begin{array}{c}1945-1971 \\
\text { vs 1971- } \\
1984\end{array}$ & $\begin{array}{c}1971-1984 \\
\text { vs 1984- } \\
2008\end{array}$ & $\begin{array}{c}1984-2008 \\
\text { vs 2008- } \\
2016\end{array}$ \\
\hline Technology & -67.93 & $389.22^{*}$ & $-80.70^{*}$ & 9.90 & -43.30 \\
Shock & $-69.14^{*}$ & 19.56 & $-33.13^{*}$ & -53.16 & -42.28 \\
Price Shock & 34.56 & $33.34 *$ & $-90.16^{*}$ & $0.64 *$ & -71.25 \\
Money Shock & $-34.82^{*}$ & $-29.12^{*}$ & $-49.12^{*}$ & $-12.10^{*}$ & -64.10 \\
Transitory & $-98.81^{*}$ & 117.77 & 69.71 & 91.86 & -61.60 \\
Shock & Unconditional & -
\end{tabular}

Notes: All number are percentages. Statistically significant changes at the 5\% level of significance (the lower bound of the preceding peak exceeds the upper bound of the following trough) are marked with an asterisk. Negative values denote reductions in volatility. 
Table 2: Changes in volatility over different time periods for U.K. house prices

\begin{tabular}{l|c|c|c|c|c}
\hline & $\begin{array}{c}1880-1930 \\
\text { vs 1930- } \\
1945\end{array}$ & $\begin{array}{c}1930-1945 \\
\text { vs } 1945- \\
1971\end{array}$ & $\begin{array}{c}1945-1971 \\
\text { vs } 1971-\end{array}$ & $\begin{array}{c}1971-1984 \\
\text { vs 1984- } \\
2008\end{array}$ & $\begin{array}{c}1984-2008 \\
\text { vs 2008- } \\
2016\end{array}$ \\
\hline Technology & -59.84 & 171.31 & 62.71 & $-61.92^{*}$ & -79.56 \\
Shock & -68.43 & 62.98 & 39.95 & 12.18 & -79.74 \\
Price Shock & -12.41 & 103.58 & -17.22 & -3.67 & -35.26 \\
Money Shock & -54.69 & 104.78 & -54.87 & $214.10^{*}$ & -48.51 \\
Transitory & $-98.16^{*}$ & 624.31 & -64.53 & 188.90 & -66.95 \\
Shock & Unconditional & &
\end{tabular}

Notes: All number are percentages. Statistically significant changes (the lower bound of the preceding peak exceeds the upper bound of the following trough) at the $5 \%$ level of significance are marked with an asterisk. Negative values denote reductions in volatility. 


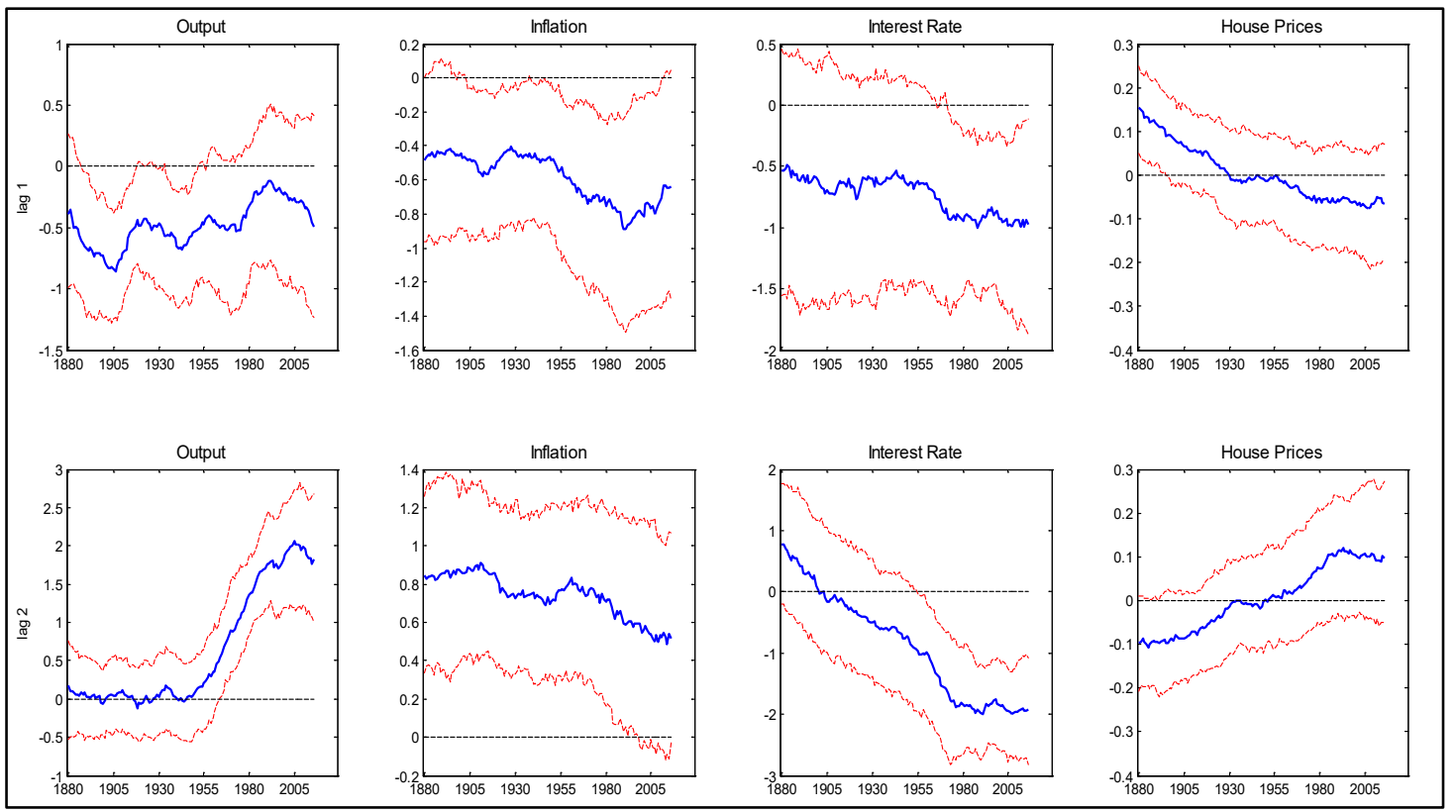

Figure 1: U.S. Posterior median coefficients estimates and their $68 \%$ intervals for house prices. We report Lag 1 and Lag 2. 


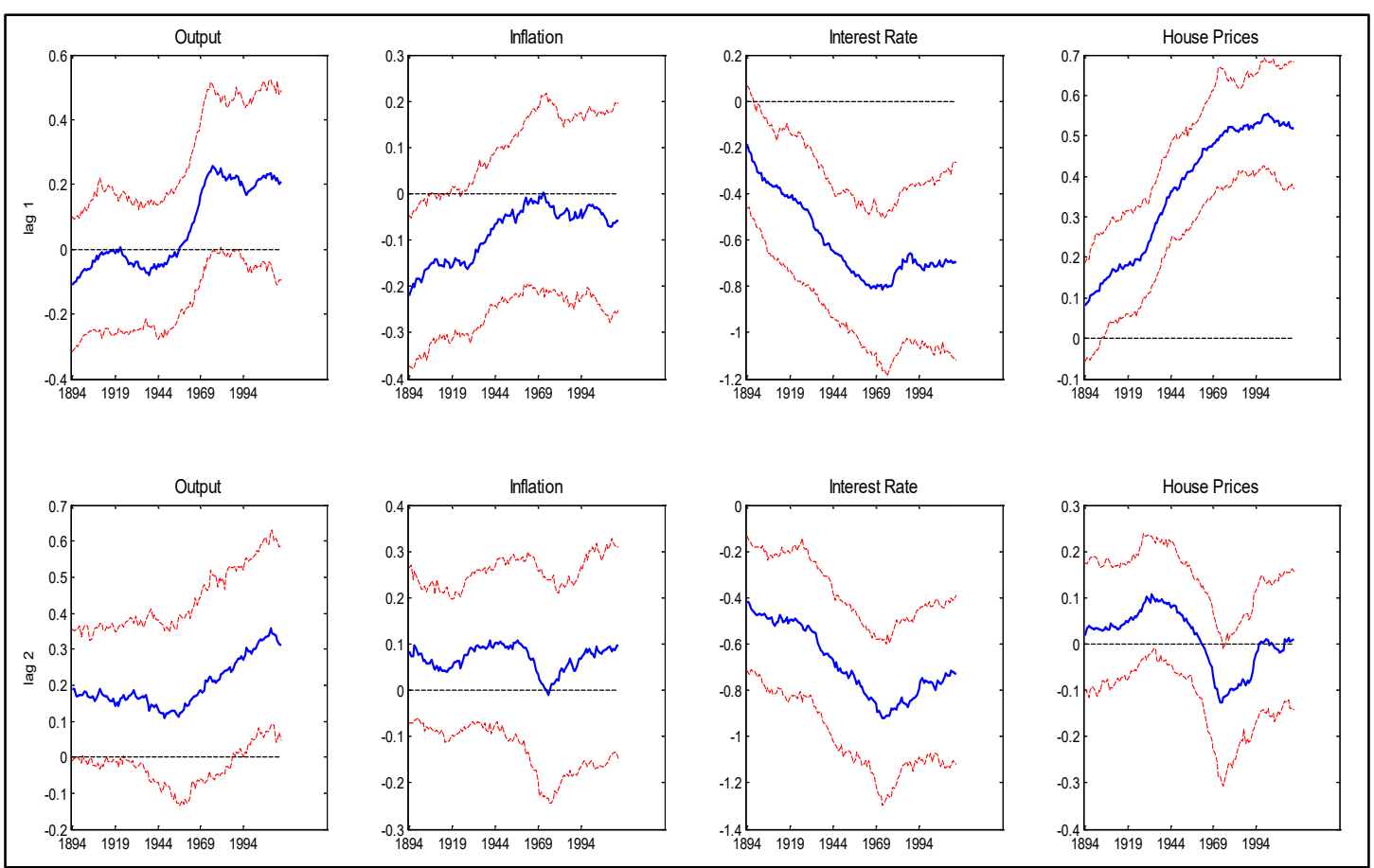

Figure 2: U.K. Posterior median coefficients estimates and their $68 \%$ intervals for house prices. Lag 1 and Lag 2. 


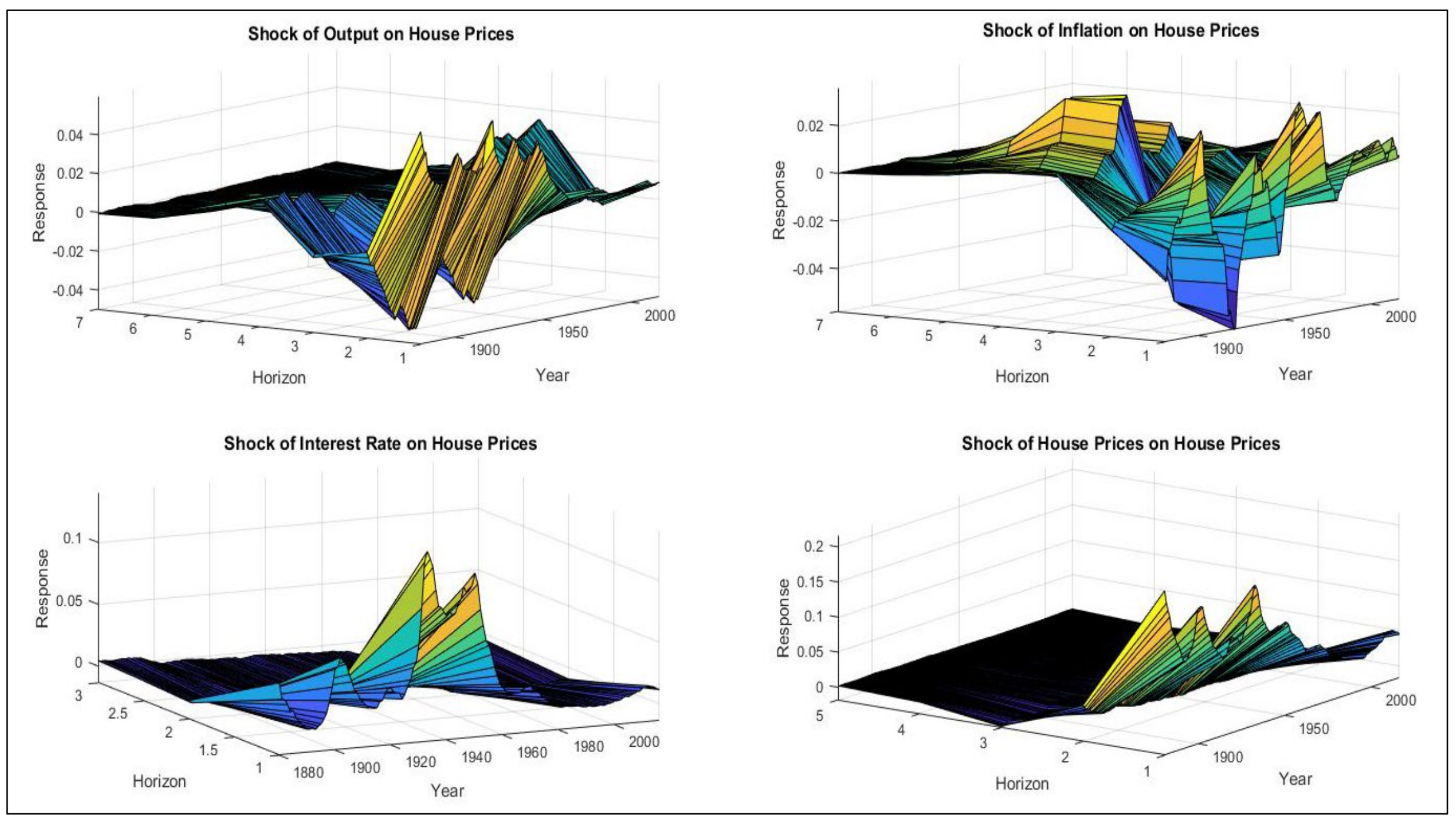

Figure 3: Impulse Response Functions of the time-varying model for the U.S. 

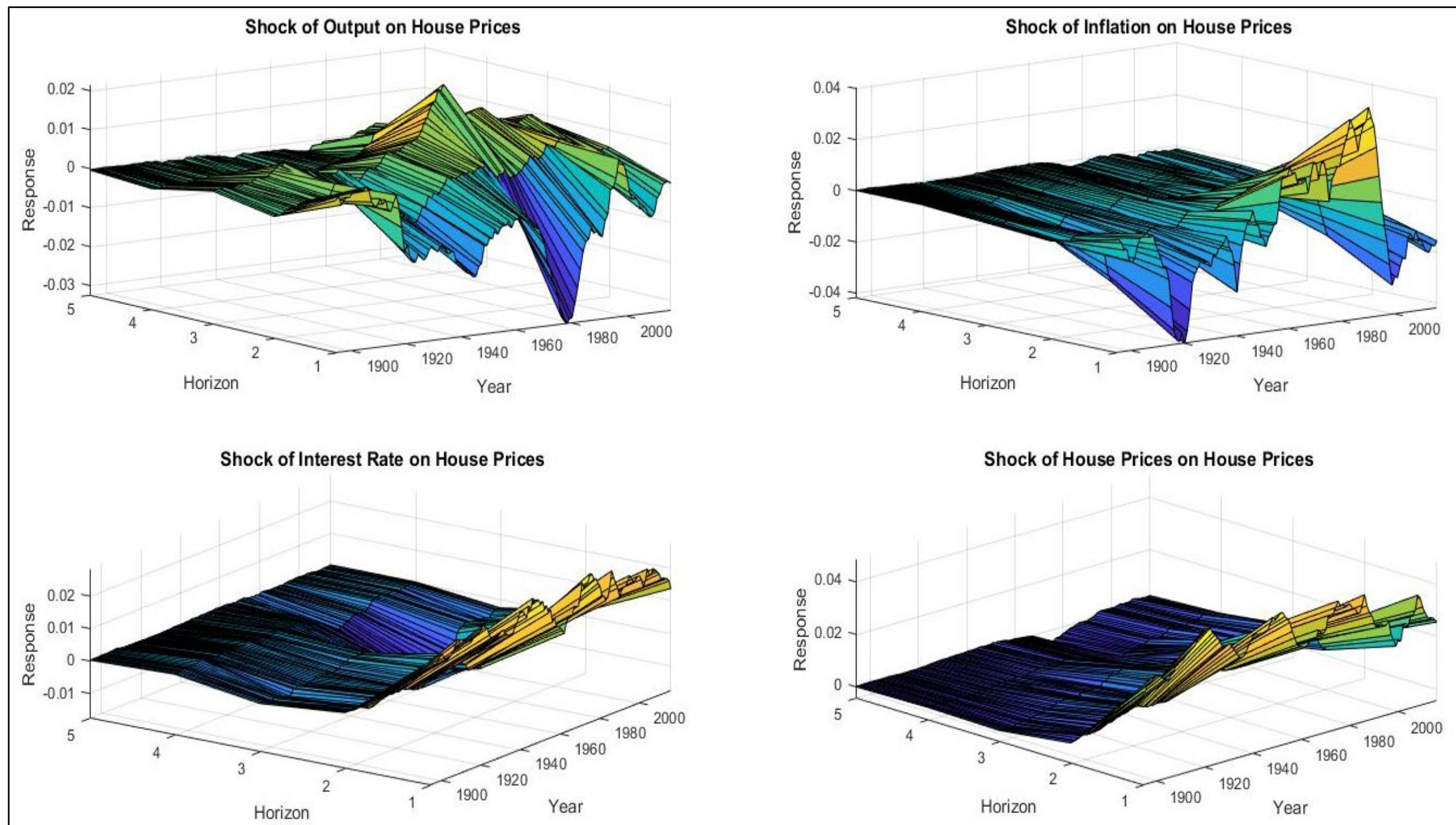

Figure 4: Impulse Response Functions of the time-varying model for the U.K 


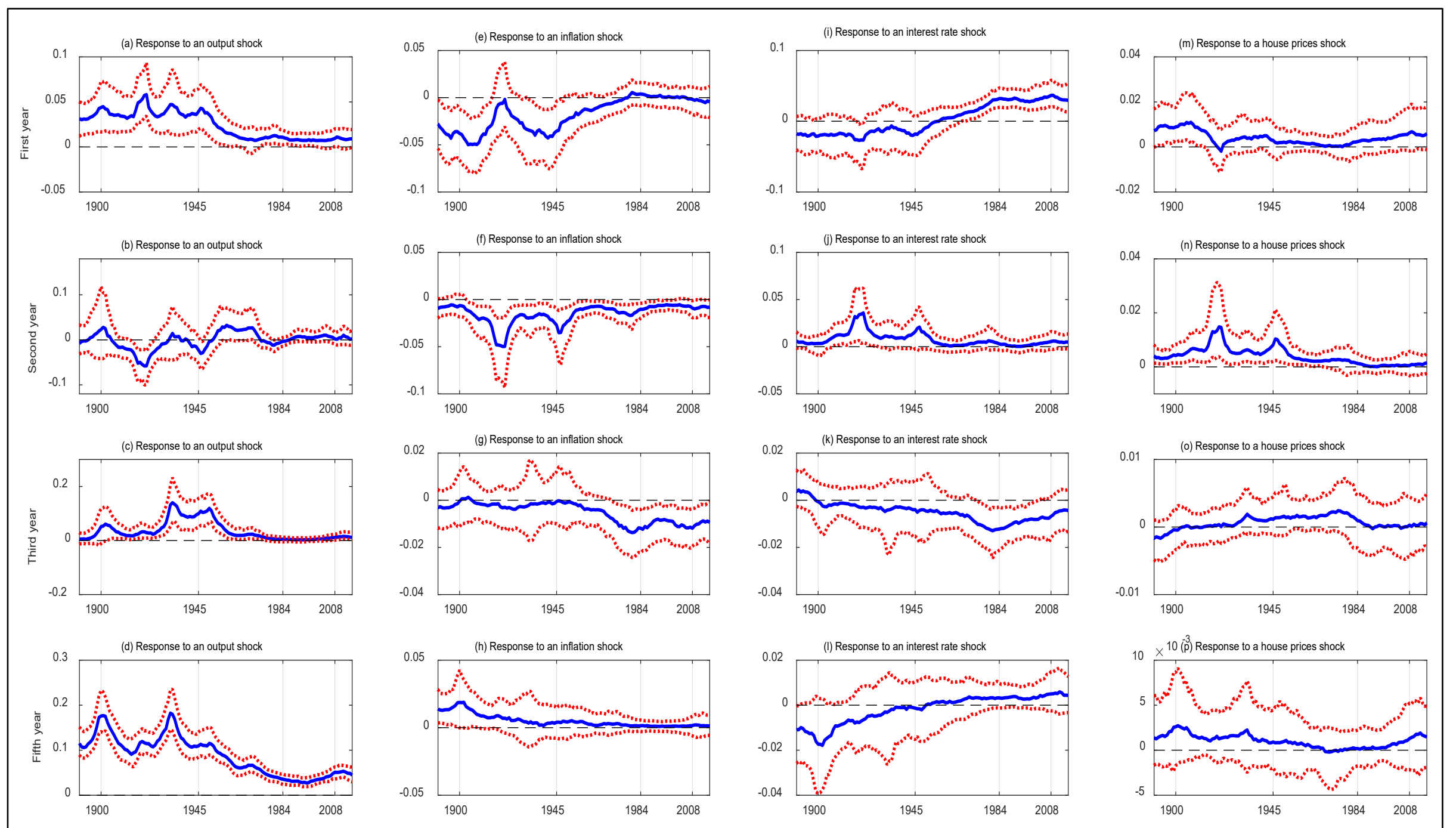

Figure 5: Horizon dependent Impulse Response Functions of the time-varying model for the U.S with $16^{\text {th }}$ and $84^{\text {th }}(1$ std) percentiles for house prices. 

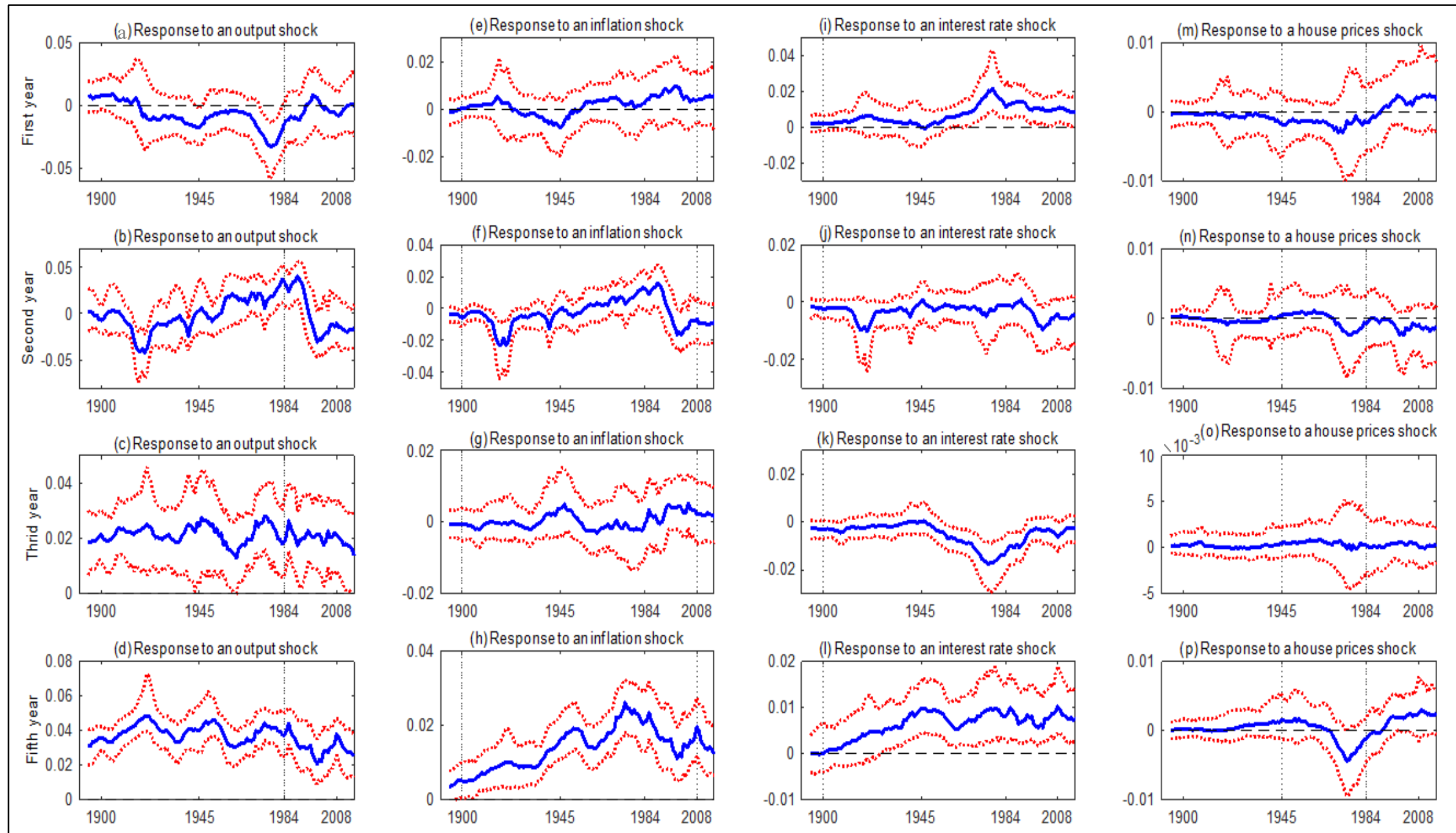

Figure 6: Horizon dependent Impulse Response Functions of the time-varying model for the U.K with the $16^{\text {th }}$ and $84^{\text {th }}$ (1 std) percentiles for house prices. 


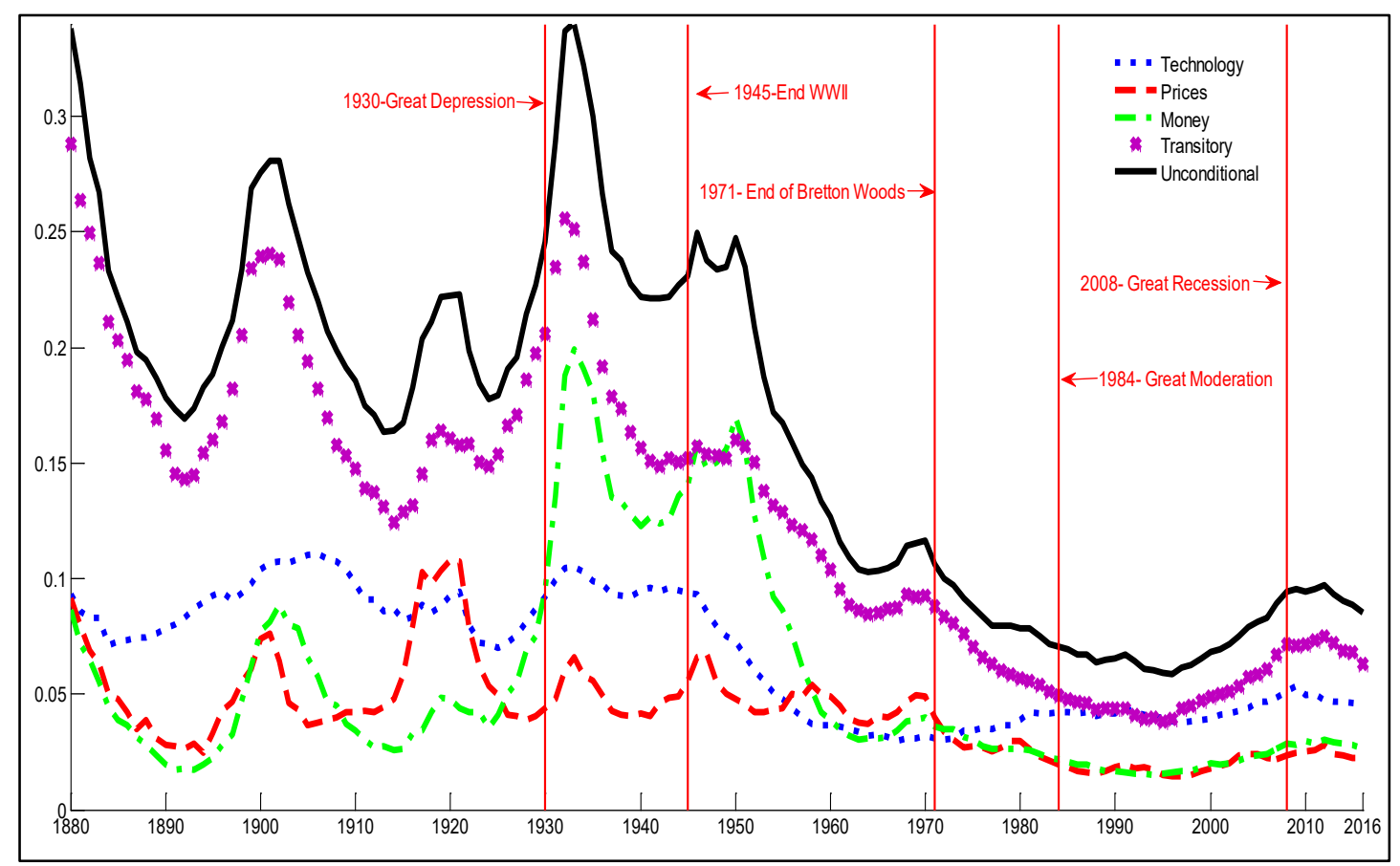

Figure 7: Unconditional and conditional standard deviations for the U.S. The solid (black) line depicts the unconditional standard deviation, the dotted (blue) is the conditional deviation on a technology (output) shock, the dashed (red) line the conditional deviation of a prices (inflation) shock, the line-dotted (green) line the conditional shock on a money (interest rate) shock and the line marked with an $\mathrm{x}$ (purple) the conditional deviation on the transitory shock 


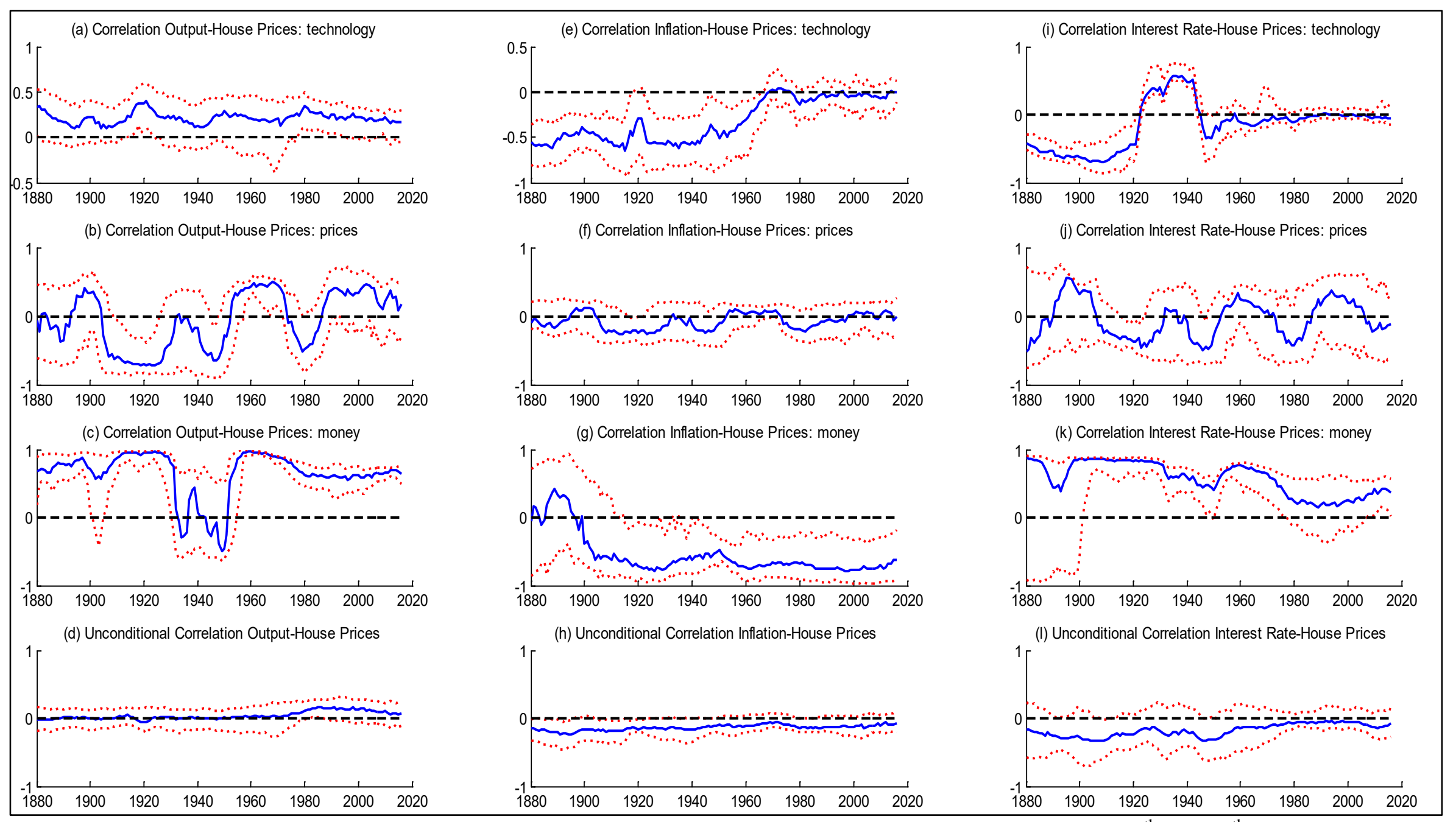

Figure 8: Unconditional and conditional correlation on the macro shocks for the U.S with the corresponding $16^{\text {th }}$ and $84^{\text {th }}$ percentiles. 


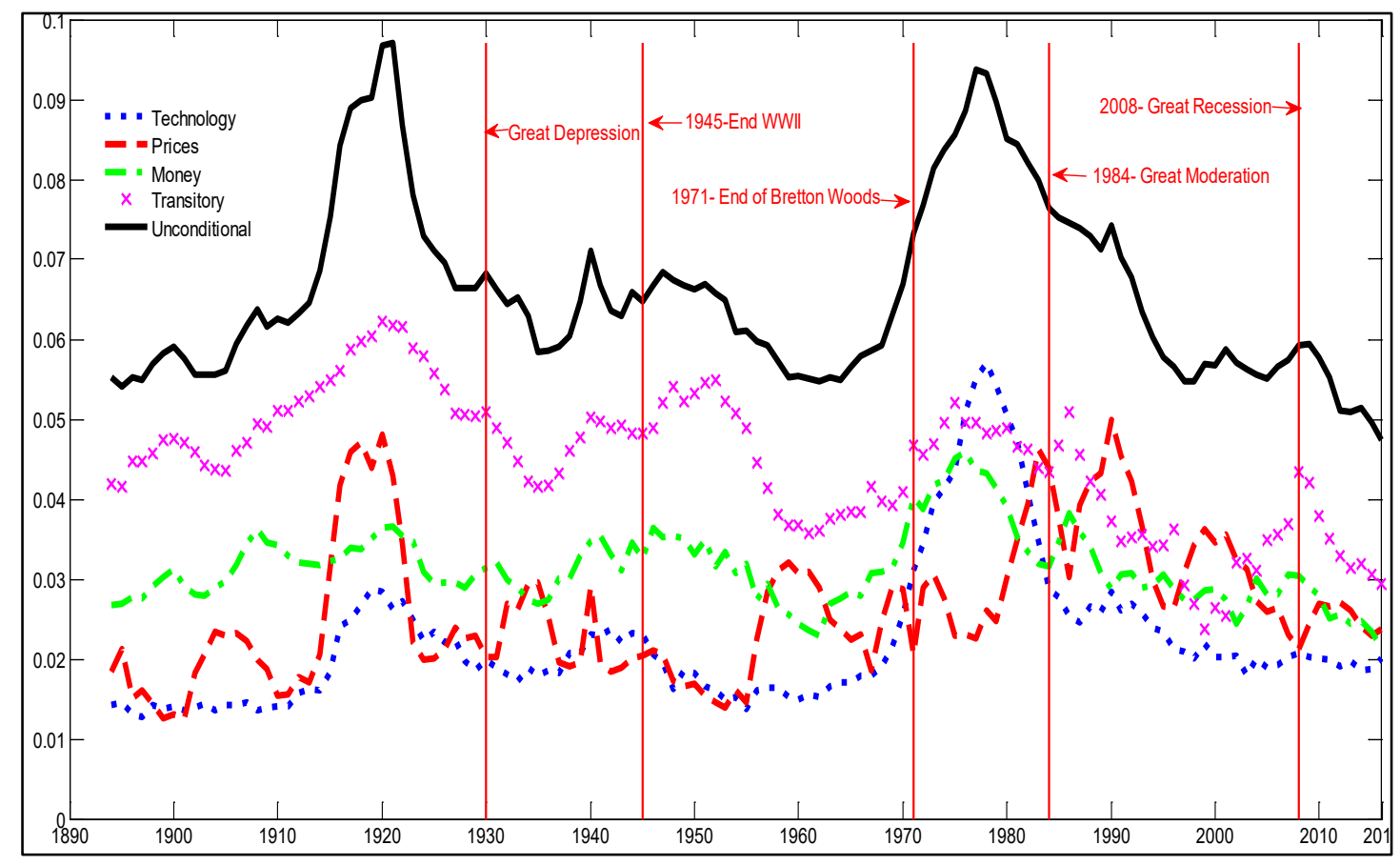

Figure 9: Unconditional and conditional standard deviations for the U.K. The solid (black) line depicts the unconditional standard deviation, the dotted (blue) is the conditional deviation on a technology (output) shock, the dashed (red) line the conditional deviation of a prices (inflation) shock, the line-dotted (green) line the conditional shock on a money (interest rate) shock and the line marked with an $\mathrm{x}$ (purple) the conditional deviation on the transitory shock. 


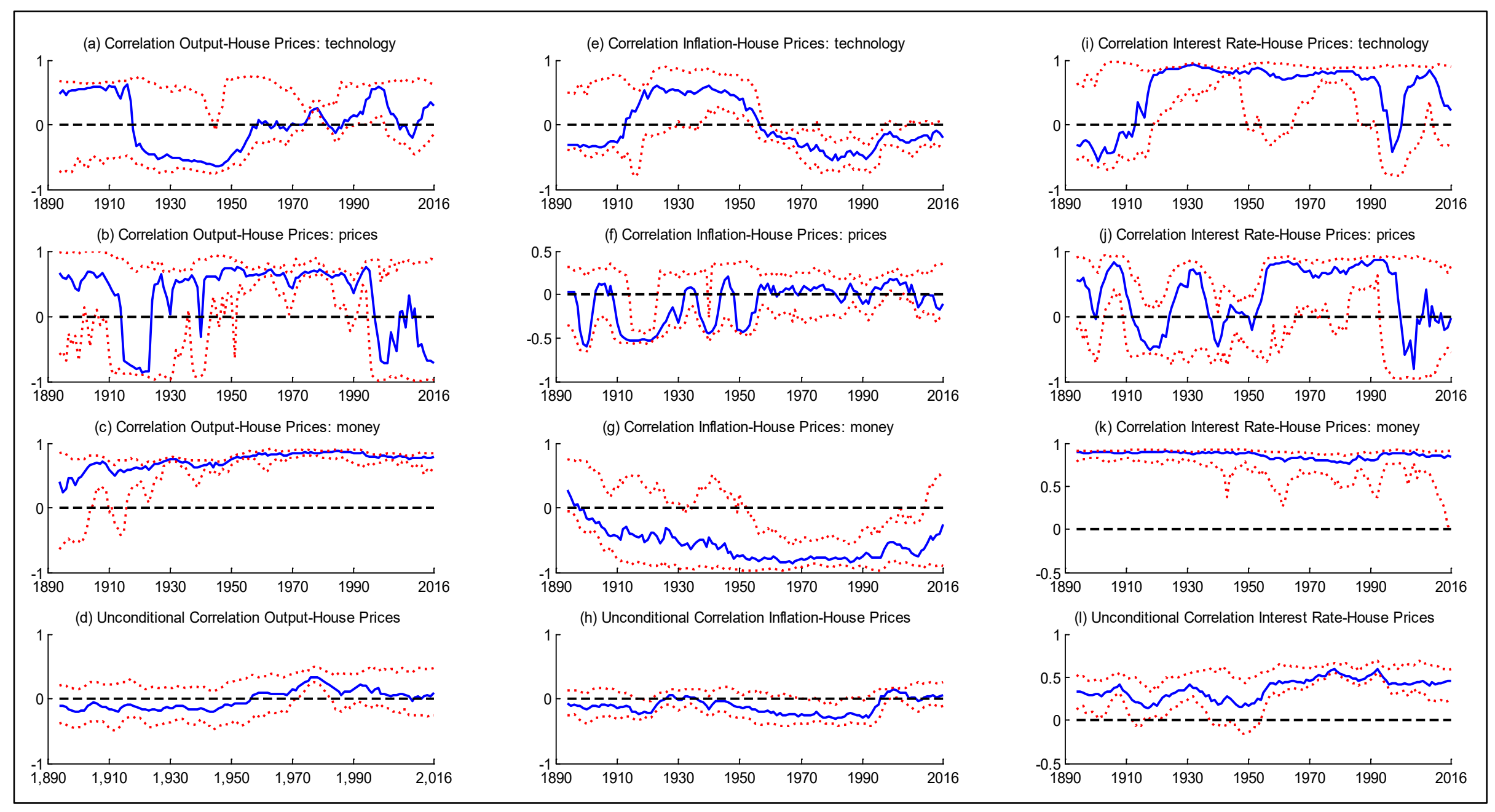

Figure 10: Unconditional and conditional posterior median correlations on the macro shocks for the U.K with the corresponding $16^{\text {th }}$ and $84^{\text {th }}$ percentiles. 


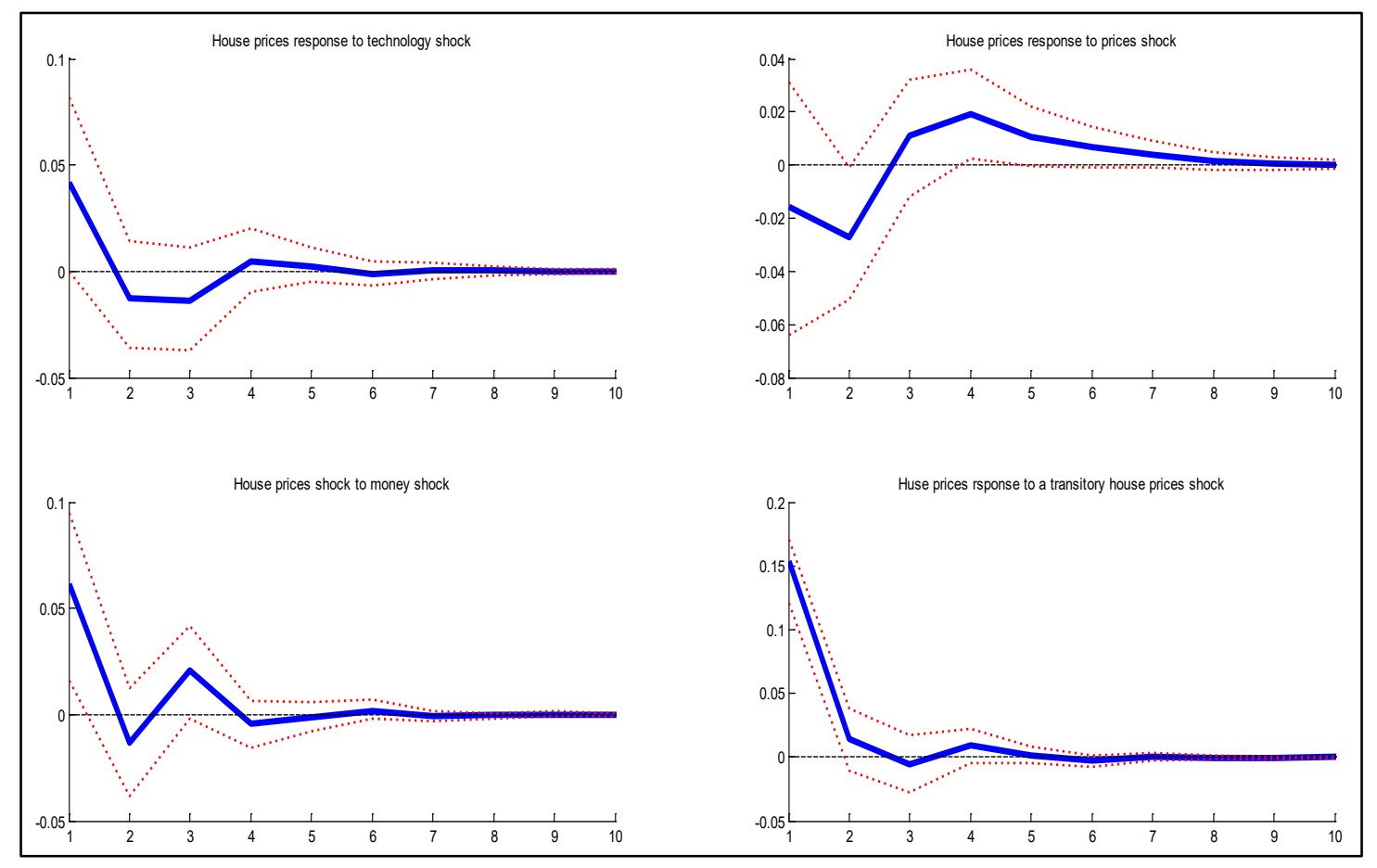

Figure 11: Impulse responses of house prices to macroeconomic shocks with 1 standard deviation band for the U.S. 


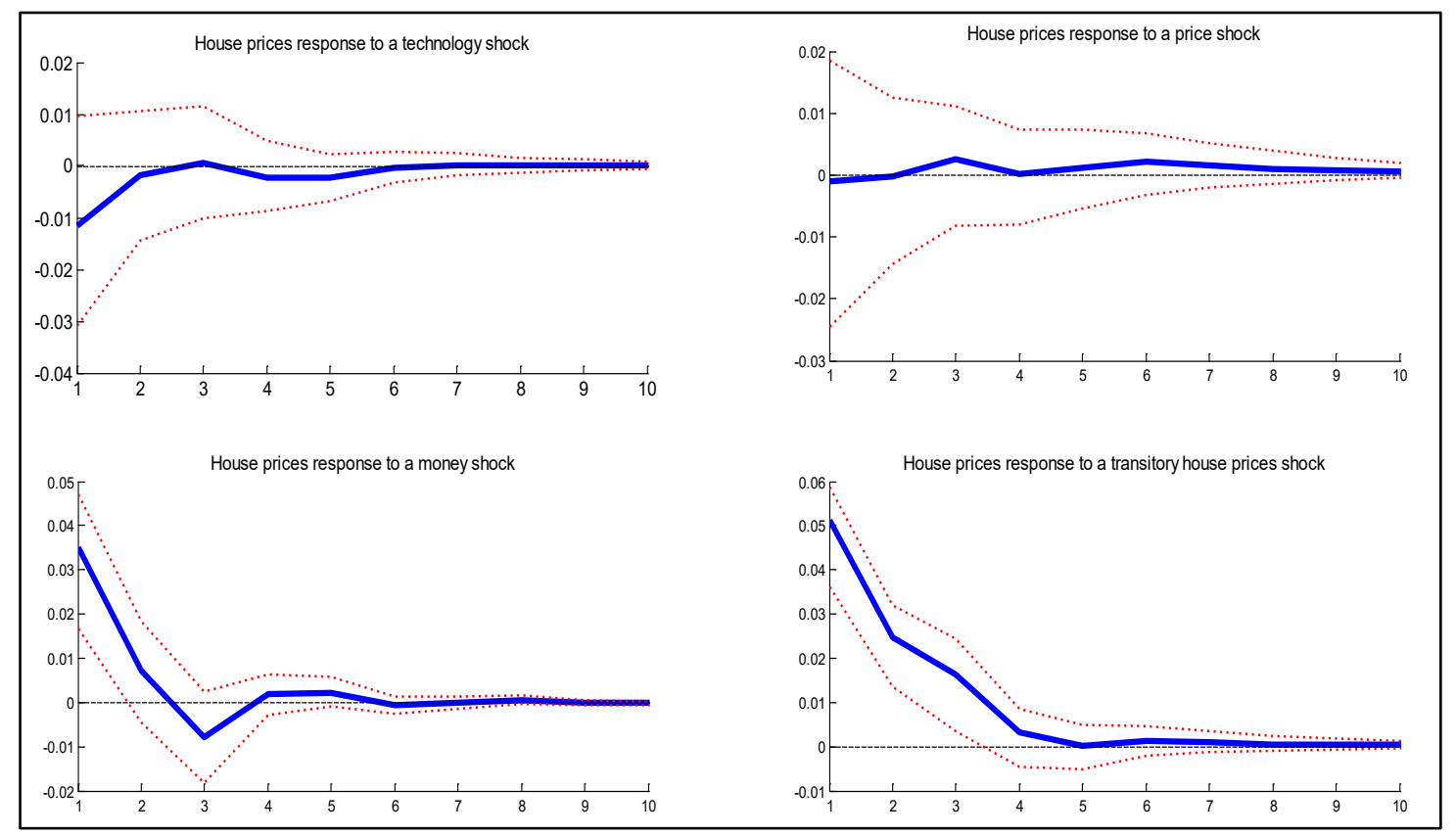

Figure 12: Impulse responses of house prices to macroeconomic shocks with 1 standard deviation bands for the U.K. 


\section{Appendix}

\section{Appendix A: Estimation of the TVP-VARs models}

Our estimation procedure draws directly from Canova and Gambetti (2010).

\section{Priors}

Let $z^{T}$ dente the sequence of $z$ s up to time T. Let $\gamma$ be the vector containing the nonzero elements of $F^{-1}$ that are different from one and are stacked in rows and $\Xi$ a vector including all the $\Xi_{i}$. The transition density is assumed to be

$$
\begin{gathered}
p\left(\theta_{t} \mid \theta_{t-1}, \Omega\right) \propto I\left(\theta_{t}\right) f\left(\theta_{t} \mid \theta_{t-1}, \Omega\right) \\
p\left(\theta_{t} \mid \theta_{t-1}, \Omega\right)=N\left(\theta_{t-1}, \Omega\right)
\end{gathered}
$$

Where $I\left(\theta_{t}\right)$ is an indicator function selecting non-explosive draws of $\theta_{t}$ for $y_{t}$. We assume the hyperparameters and the initial states are independent so that the joint prior is simply the product of the marginal densities. Following Cogley and Sargent (2005) we assume:

$$
\begin{gathered}
P\left(\theta_{0}\right) \propto I\left(\theta_{0}\right) N(\bar{\theta}, \bar{P}) \\
P(\Omega)=\operatorname{IW}\left(\bar{\Omega}^{-1}, T_{0}\right) \\
P\left(\log \sigma i_{0}\right)=\mathrm{N}\left(\log \bar{\sigma}_{i}, 10\right) \\
P(\gamma)=\mathrm{N}\left(0,10000 \times I_{4}\right) \\
P\left(\Xi_{i}\right)=\operatorname{IG}\left(\frac{0.01^{2}}{2}, \frac{1}{2}\right)
\end{gathered}
$$

Where $\bar{\theta}, \bar{P}$ are OLS estimates of the VAR coefficients and their variances obtained with the initial sample, $\bar{\Omega}=\lambda \overline{\mathrm{P}}, T_{0}$ is the number of observations in the initial sample (40 observations), $\bar{\sigma}_{i}$ is the estimate of the variance of the residual in equation $i$ obtained using the initial sample. The hyperparameter $\lambda$ is set to 0.0005 for all parameters except for the constant terms of output growth, inflation and interest rate. For these constants, it is set to 0.001 . 


\section{Posteriors}

To draw realizations from the posterior density we use the Gibbs sampler. Each iteration is composed of four steps and, under regularity conditions and after a burn-in period, iterations on these steps produce draws from the joint density.

\section{- $\quad$ Step 1: $p\left(\theta^{T} \mid y^{T}, \gamma, \sigma^{T}, \Xi, \Omega\right)$}

Conditional on $\left(\theta^{T} \mid y^{T}, \gamma, \sigma^{T}, \Xi, \Omega\right)$ the unrestricted posterior of the states is normal. To draw from the conditional posterior we employ the algorithm of Carter and Kohn (1994). The conditional mean and variance of the terminal state $\theta^{T}$ is computed using standard Kalman filter recursions while for all the other states the following backward recursions are employed:

$$
\begin{gathered}
\theta_{t \mid t-1}=\theta_{t \mid t}+P_{t \mid t} P_{t \mid t}^{-1}\left(\theta_{t+1}-\theta_{t \mid t}\right) \\
P_{t \mid t-1}=P_{t \mid t}-P_{t \mid t} P_{t+1 \mid t}{ }^{-1} P_{t \mid t}
\end{gathered}
$$

Where $p\left(\theta_{t} \mid \theta_{t+1}, y^{T}, \gamma, \sigma^{T}, \Xi, \Omega\right) \sim N\left(\theta_{t \mid t+1}, P_{t \mid t+1}\right)$

\section{- Step 2: $p\left(\gamma \mid y^{T}, \theta^{T}, \sigma^{T}, \Xi, \Omega\right)$}

Given that $\sigma^{T}$ and $y^{T}$ are known $\varepsilon_{t}$ is known and since $u_{t}$ is a standard Gaussian white noise, we have $D_{t}^{-1 / 2} F^{-1} \varepsilon_{t}=u_{t}$ or $D_{t}^{-1 / 2} \varepsilon_{t}=D_{t}^{-1 / 2}\left(F^{-1}-I\right) \varepsilon_{t}+u_{t}$. We can rewrite the ith equation as $z_{i t}=-w_{i t} \gamma_{i}+u_{i t}$ where $z_{i t}=\varepsilon_{i t} / \sqrt{\sigma_{i t}}, w_{i t}=$ $\left[\varepsilon_{1 t} / \sqrt{\sigma_{1 t}}, \ldots, \varepsilon_{i-1, t} / \sqrt{\sigma_{i-1, t}}\right]$ and $\gamma_{i}$ is the column vector formed by the non-zero elements of the ith row of $F^{-1}-I$. Given the normal prior, the posterior is $\gamma_{i}=$ $N\left(F_{1, i}, V_{1, i}\right)$ where $F_{1, i}=V_{0, i}\left(V_{0, i}^{-1} \gamma_{0, i}+w_{i}^{\prime} z_{i}\right)$ and $V_{1, i}=\left(V_{0, i}^{-1}+w_{i}^{\prime} w_{i}\right)$ with $V_{0, i}$ and $\gamma_{0, i}$ the prior variance and mean, respectively. Drawing for $i=2,3,4$ we obtain a draw for $\gamma$.

- $\quad$ Step 3: $p\left(\sigma^{T} \mid y^{T}, \theta^{T}, \gamma, \Xi, \Omega\right)$

The elements of $\sigma^{T}$ are drawn drawn using the univariate algorithm by Jacquier, Polson and Rossi (2004) along the lines described in Cogley and Sargent (2005) (see Appendix B.2.5 for details).

- Step 4: $p\left(\Xi_{i} \mid y^{T}, \theta^{T}, \gamma, \sigma^{T}, \Omega\right), p\left(\Omega \mid y^{T}, \theta^{T}, \gamma, \sigma^{T}, \Xi\right)$

Conditional on $y^{T}, \theta^{T}, \gamma, \sigma^{T}$ and under conjugate priors, all the remaining hyperparameters, can be sampled in a standard way from Inverted Wishart and Inverted Gamma densities (Gellman et al., 1995). We perform 20000 repetitions, discard the 
first 5000 draws and, for inference, we keep one every 10 of the remaining draws to break the autocorrelation of the draws.

\section{Appendix B: TVP-VAR parameters}

Figure B1, B2 and B3 present graphically the time-varying coefficients for the output growth, inflation and interest rate equations in the VAR for the U.S. while figures B4, B5 and B6 present the respective coefficients for the U.K.

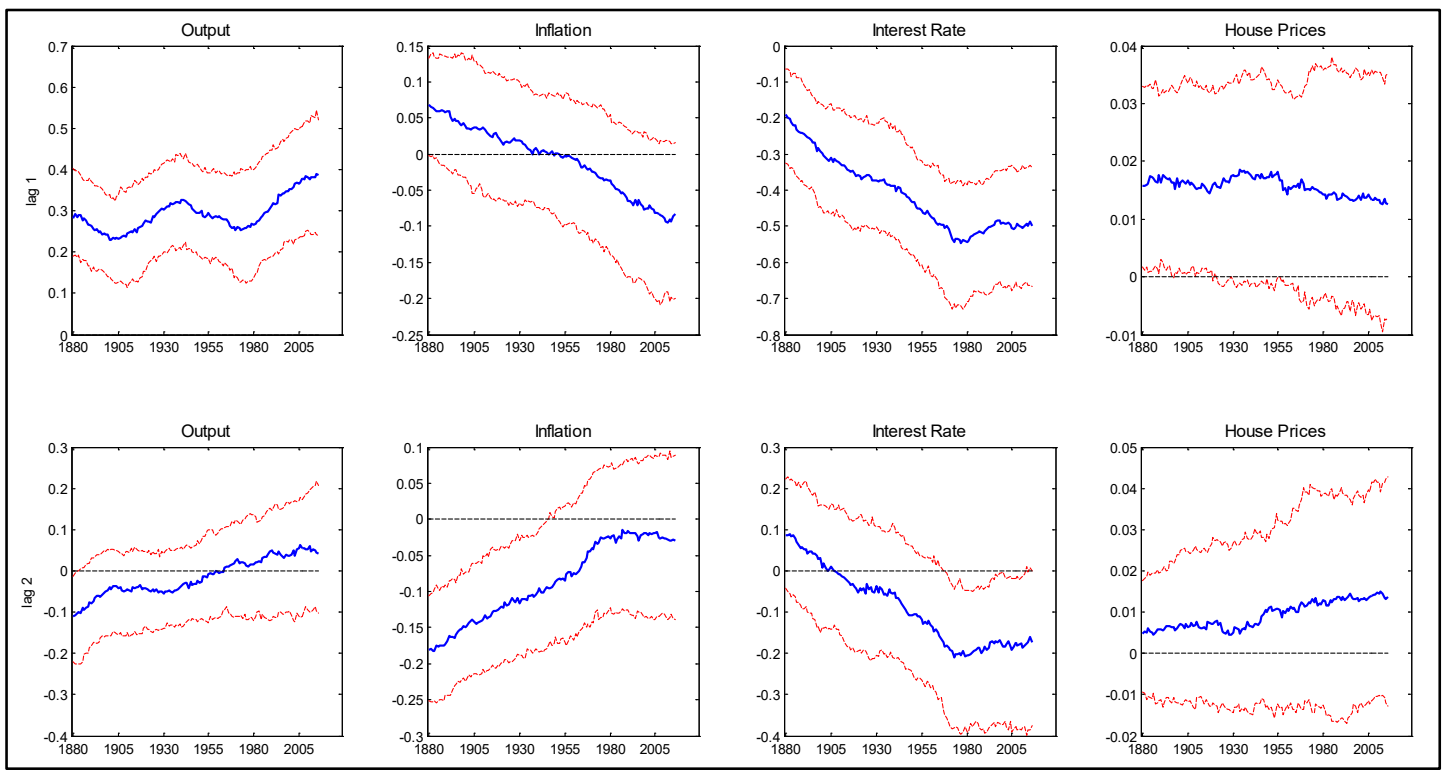

Figure B1: U.S. Posterior median coefficients estimates and their $68 \%$ intervals for output growth equation.

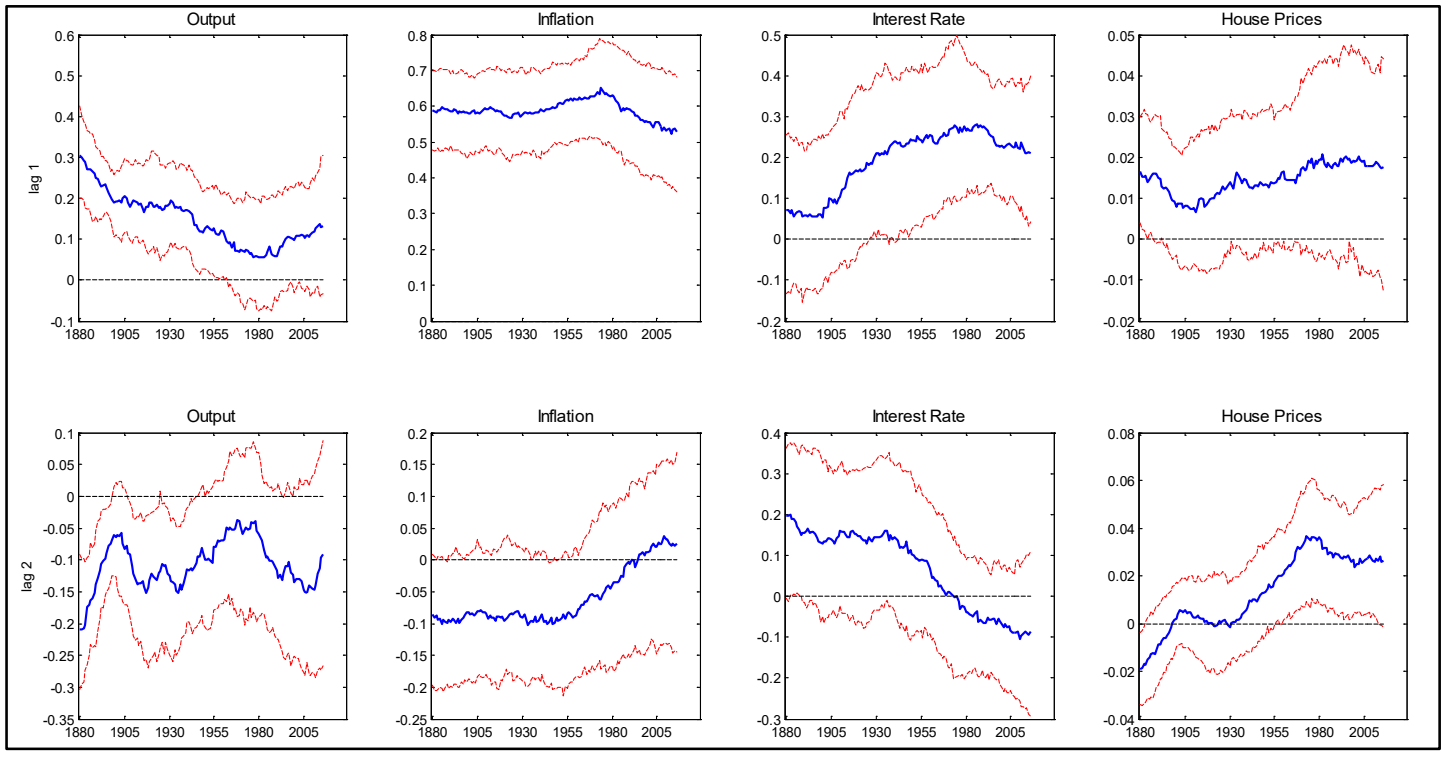

Figure B2: U.S. Posterior median coefficients estimates and their $68 \%$ intervals for inflation equation. 


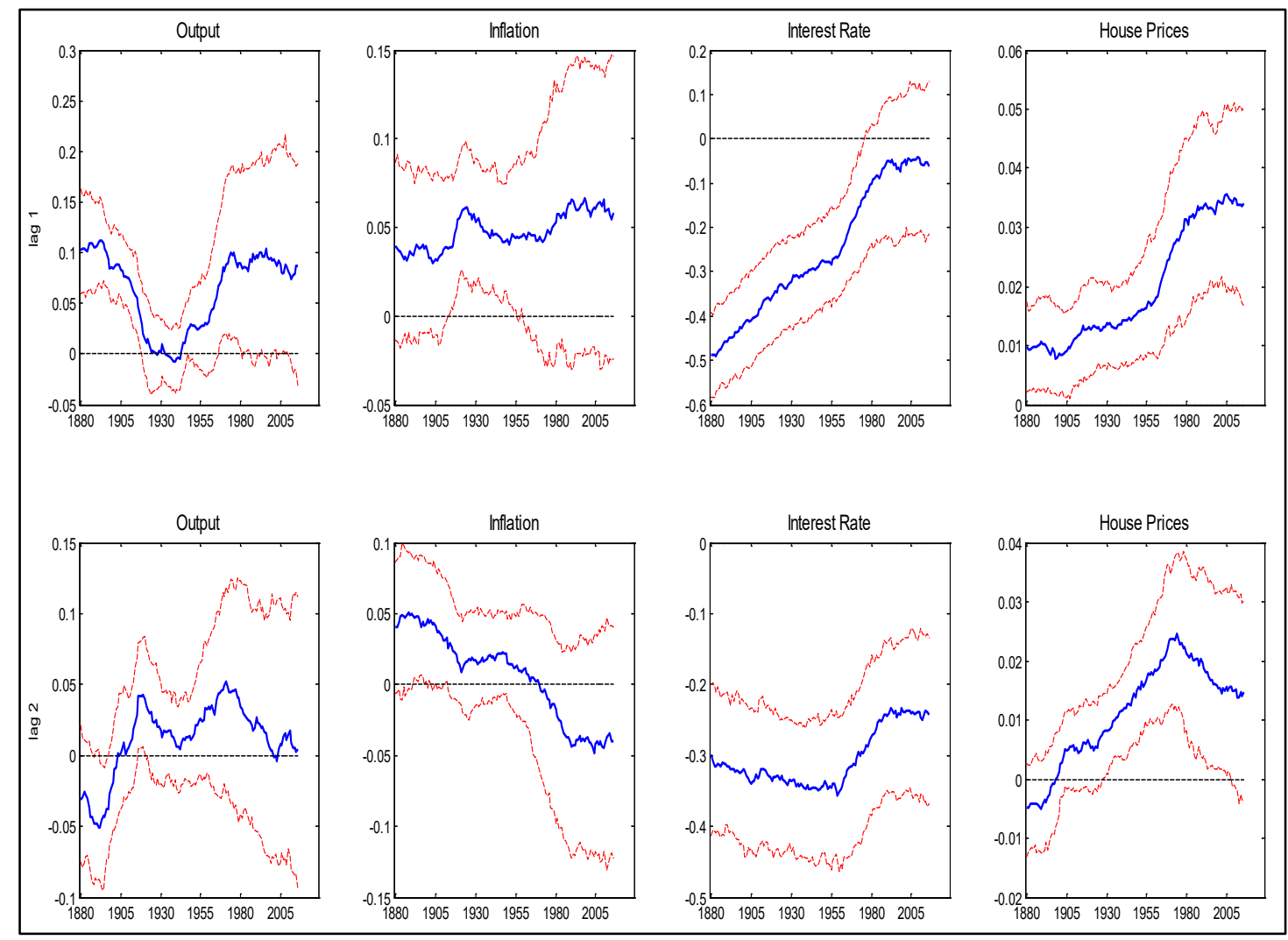

Figure B3: U.S. Posterior median coefficients estimates and their $68 \%$ intervals for interest rates equation.

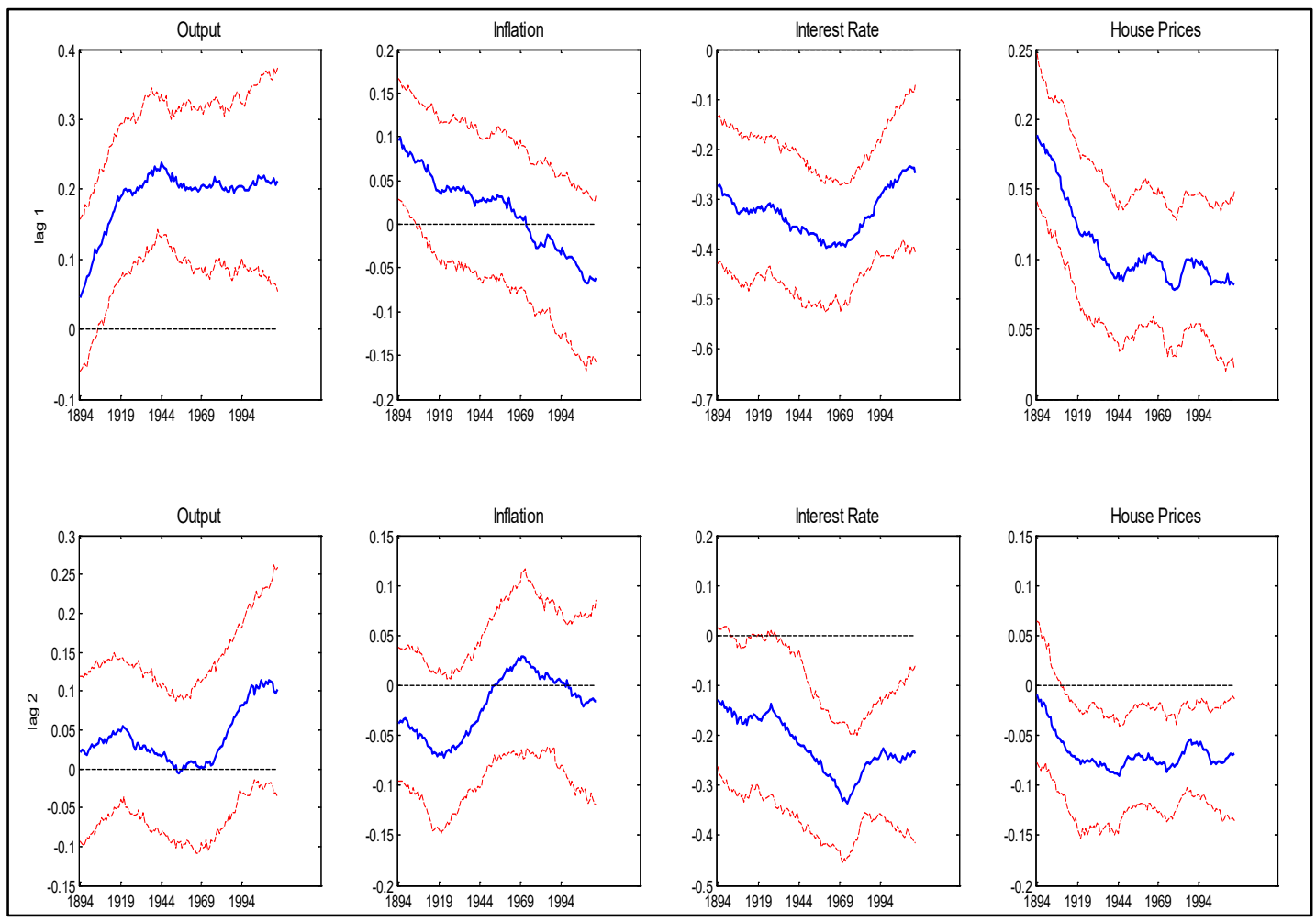

Figure B4: U.K. Posterior median coefficients estimates and their $68 \%$ intervals for output growth equation. 


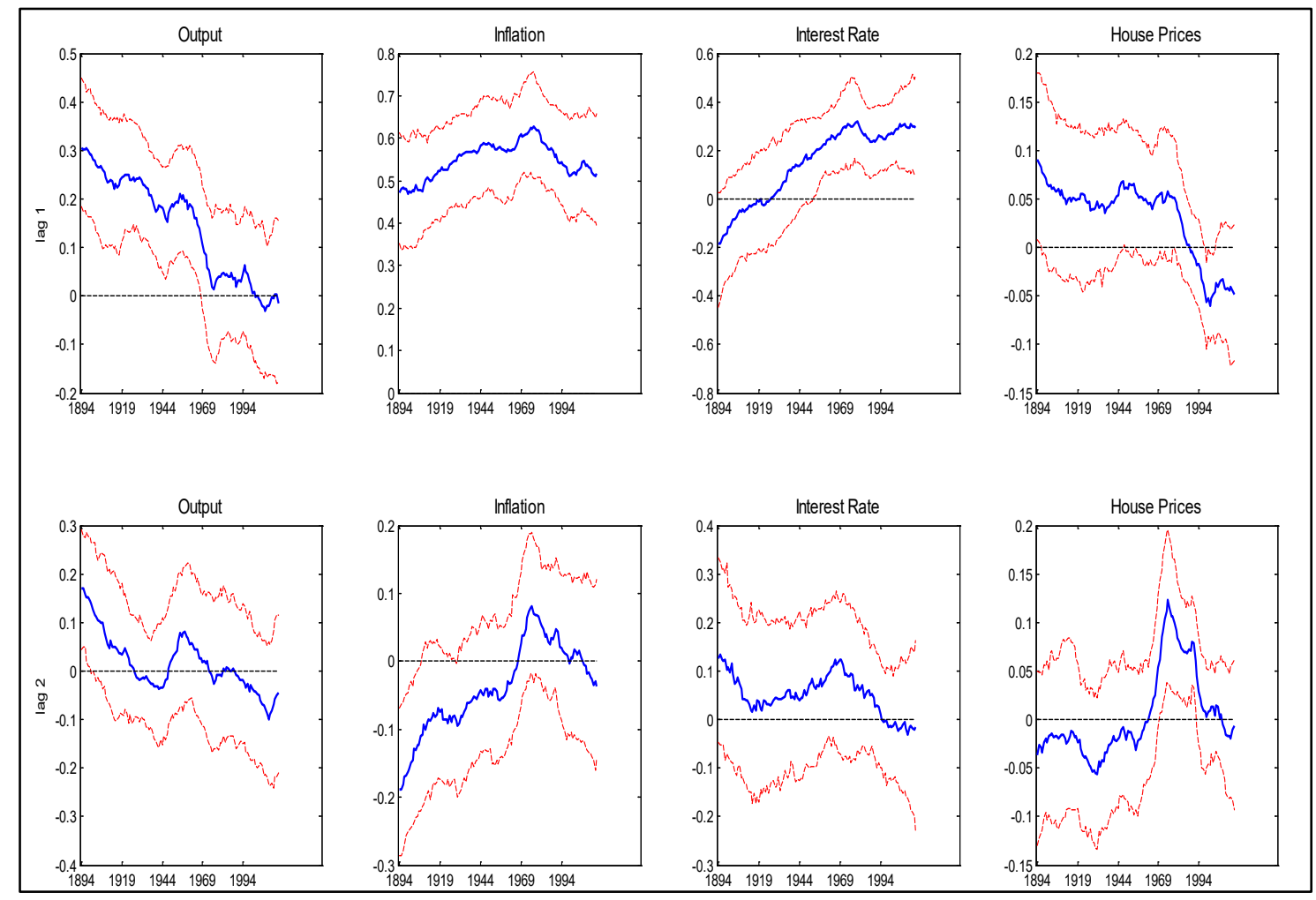

Figure B5: U.K. Posterior median coefficients estimates and their $68 \%$ intervals for inflation equation.

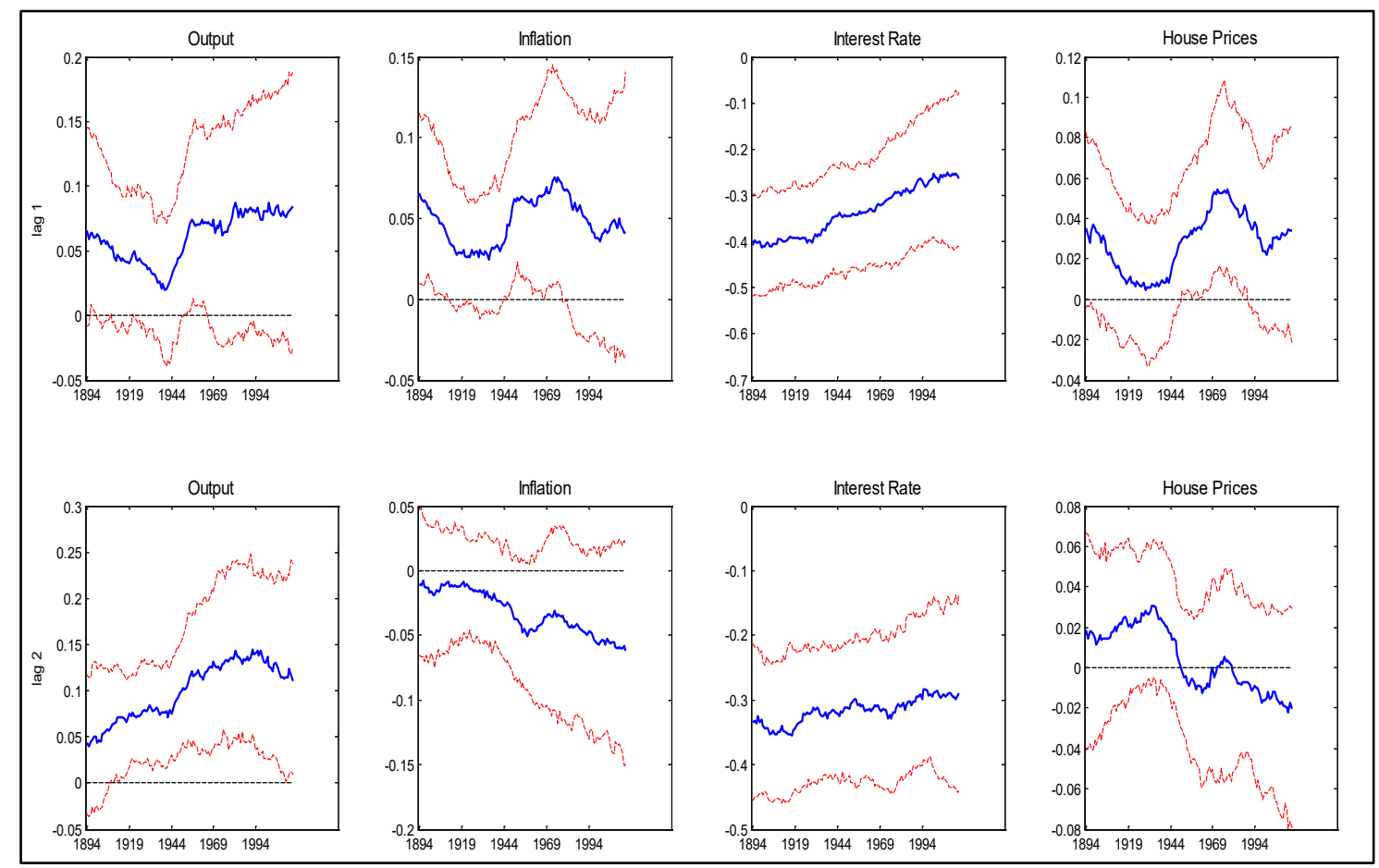

Figure B6: U.K. Posterior median coefficients estimates and their $68 \%$ intervals for interest rates equation. 
Appendix C: Volatility evolution

\begin{tabular}{|c|c|c|c|c|c|c|c|}
\hline \multicolumn{8}{|c|}{ Table C1: US volatility evolution } \\
\hline & & $1880-1930$ & $1930-1945$ & $1945-1971$ & 1971-1984 & $1984-2008$ & $2008-2016$ \\
\hline \multirow{3}{*}{$\begin{array}{l}\text { Technology } \\
\text { Shock }\end{array}$} & Local peak & $\begin{array}{c}0.11 \\
(1906) \\
{[0.1056]}\end{array}$ & $\begin{array}{c}0.11 \\
(1933) \\
{[0.0973]}\end{array}$ & $\begin{array}{c}0.09 \\
(1945) \\
{[0.0878]}\end{array}$ & $\begin{array}{c}0.04 \\
(1984) \\
{[0.0409]}\end{array}$ & $\begin{array}{c}0.05 \\
(2008) \\
{[0.0491]}\end{array}$ & $\begin{array}{c}0.05 \\
(2009) \\
{[0.0497]}\end{array}$ \\
\hline & Local trough & $\begin{array}{c}0.07 \\
(1925) \\
{[0.0781]}\end{array}$ & $\begin{array}{c}0.09 \\
(1930) \\
{[0.1095]}\end{array}$ & $\begin{array}{c}0.03 \\
(1967) \\
{[0.0414]}\end{array}$ & $\begin{array}{c}0.03 \\
(1972) \\
{[0.0403]}\end{array}$ & $\begin{array}{c}0.04 \\
(1997) \\
{[0.0507]}\end{array}$ & $\begin{array}{c}0.05 \\
(2016) \\
{[0.0618]}\end{array}$ \\
\hline & Change & & -67.93 & $389.22 *$ & $-80.70^{*}$ & 9.90 & -43.30 \\
\hline \multirow{3}{*}{ Prices Shock } & Local peak & $\begin{array}{c}0.11 \\
(1920) \\
{[0.0910]}\end{array}$ & $\begin{array}{c}0.07 \\
(1933) \\
{[0.0415]}\end{array}$ & $\begin{array}{c}0.07 \\
(1947) \\
{[0.0593]}\end{array}$ & $\begin{array}{c}0.04 \\
(1971) \\
{[0.0261]}\end{array}$ & $\begin{array}{c}0.02 \\
(2005) \\
{[0.0160]}\end{array}$ & $\begin{array}{c}0.03 \\
(2012) \\
{[0.0211]}\end{array}$ \\
\hline & Local trough & $\begin{array}{c}0.03 \\
(1894) \\
{[0.0867]}\end{array}$ & $\begin{array}{c}0.04 \\
(1939) \\
{[0.0735]}\end{array}$ & $\begin{array}{c}0.04 \\
(1964) \\
{[0.0878]}\end{array}$ & $\begin{array}{c}0.02 \\
(1984) \\
{[0.0257]}\end{array}$ & $\begin{array}{c}0.01 \\
(1996) \\
{[0.0323]}\end{array}$ & $\begin{array}{c}0.02 \\
(2016) \\
{[0.0415]}\end{array}$ \\
\hline & Change & & $-69.14 *$ & 19.56 & $-33.13^{*}$ & -53.16 & $-42.28^{*}$ \\
\hline \multirow{3}{*}{ Money Shock } & Local peak & $\begin{array}{c}0.09 \\
(1930) \\
{[0.0500]}\end{array}$ & $\begin{array}{c}0.20 \\
(1933) \\
{[0.1090]}\end{array}$ & $\begin{array}{c}0.17 \\
(1950) \\
{[0.1051]}\end{array}$ & $\begin{array}{c}0.04 \\
(1971) \\
{[0.0263]}\end{array}$ & $\begin{array}{c}0.03 \\
(2008) \\
{[0.0243]}\end{array}$ & $\begin{array}{c}0.03 \\
(2012) \\
{[0.0255]}\end{array}$ \\
\hline & Local trough & $\begin{array}{c}0.02 \\
(1891) \\
{[0.0431]}\end{array}$ & $\begin{array}{c}0.10 \\
(1930) \\
{[0.1737]}\end{array}$ & $\begin{array}{c}0.03 \\
(1963) \\
{[0.0605]}\end{array}$ & $\begin{array}{c}0.02 \\
(1984) \\
{[0.0265]}\end{array}$ & $\begin{array}{c}0.02 \\
(1994) \\
{[0.0184]}\end{array}$ & $\begin{array}{c}0.03 \\
(2016) \\
{[0.0436]}\end{array}$ \\
\hline & Change & & 34.56 & $33.34^{*}$ & $-90.16^{*}$ & $0.64 *$ & -71.25 \\
\hline \multirow{3}{*}{$\begin{array}{l}\text { Transitory } \\
\text { Shock }\end{array}$} & Local peak & $\begin{array}{c}0.29 \\
(1880) \\
{[0.2361]}\end{array}$ & $\begin{array}{c}0 . .26 \\
(1932) \\
{[0.2180]}\end{array}$ & $\begin{array}{c}0.16 \\
(1950) \\
{[0.1328]} \\
\end{array}$ & $\begin{array}{c}0.09 \\
(1971) \\
{[0.0736]}\end{array}$ & $\begin{array}{c}0.07 \\
(2008) \\
{[0.0560]} \\
\end{array}$ & $\begin{array}{c}0.08 \\
(2012) \\
{[0.0634]} \\
\end{array}$ \\
\hline & Local trough & $\begin{array}{c}0.12 \\
(1914) \\
{[0.1667]}\end{array}$ & $\begin{array}{c}0.15 \\
(1942) \\
{[0.1858]}\end{array}$ & $\begin{array}{c}0.09 \\
(1964) \\
{[0.1086]}\end{array}$ & $\begin{array}{c}0.05 \\
(1984) \\
{[0.0642]}\end{array}$ & $\begin{array}{c}0.04 \\
(1995) \\
{[0.0527]}\end{array}$ & $\begin{array}{c}0.06 \\
(2016) \\
{[0.0838]}\end{array}$ \\
\hline & Change & & $-34.82^{*}$ & $-29.12^{*}$ & $-49.12^{*}$ & $-12.10^{*}$ & $-64.10^{*}$ \\
\hline \multirow{3}{*}{$\begin{array}{l}\text { Unconditional } \\
\text { Volatility }\end{array}$} & Local peak & $\begin{array}{c}0.70 \\
(1880) \\
{[0.9685]}\end{array}$ & $\begin{array}{c}0.29 \\
(1945) \\
{[0.2876}\end{array}$ & $\begin{array}{c}0.30 \\
(1971) \\
{[0.2982]}\end{array}$ & $\begin{array}{c}0.32 \\
(1983) \\
{[0.3165]}\end{array}$ & $\begin{array}{c}0.35 \\
(2008) \\
{[0.3514]}\end{array}$ & $\begin{array}{c}0.37 \\
(2016) \\
0.3649]\end{array}$ \\
\hline & Local trough & $\begin{array}{c}0.29 \\
(1930) \\
{[0.2852]}\end{array}$ & $\begin{array}{c}0.28 \\
(1939) \\
{[0.3487]}\end{array}$ & $\begin{array}{c}0.29 \\
(1946) \\
{[0.6116]}\end{array}$ & $\begin{array}{c}0.30 \\
(1971) \\
{[0.6985]}\end{array}$ & $\begin{array}{c}0.32 \\
(1984) \\
{[0.6985]}\end{array}$ & $\begin{array}{c}0.35 \\
(2008) \\
{[0.6985]}\end{array}$ \\
\hline & Change & & $-98.81 *$ & 117.77 & 69.71 & 91.86 & -61.60 \\
\hline
\end{tabular}

Notes: Changes are in percentages. Negative values denote reductions in volatility. Local peaks/troughs are extrema values of standard deviation for the sub-sample with the year of the extrema reported in parenthesis and the corresponding lowest value of the peak/ highest value of the local trough from the $16^{\text {th }}-84^{\text {th }}$ percentiles of the distribution in brackets. Statistically significant changes at the $5 \%$ level of significance are denoted with an asterisk. 


\begin{tabular}{|c|c|c|c|c|c|c|c|}
\hline \multicolumn{8}{|c|}{$\begin{array}{c}\text { Table C2: U.K. volatility evolution } \\
\end{array}$} \\
\hline & & $1880-1930$ & $1930-1945$ & $1945-1971$ & 1971-1984 & 1984-2008 & $2008-2016$ \\
\hline \multirow{3}{*}{$\begin{array}{c}\text { Technology } \\
\text { Shock }\end{array}$} & Local peak & $\begin{array}{c}0.03 \\
(1919) \\
{[0.0139]} \\
\end{array}$ & $\begin{array}{c}0.02 \\
(1942) \\
{[0.0147]} \\
\end{array}$ & $\begin{array}{c}0.03 \\
(1971) \\
{[0.0226]} \\
\end{array}$ & $\begin{array}{c}0.06 \\
(1978) \\
{[0.0488]} \\
\end{array}$ & $\begin{array}{c}0.03 \\
(1984) \\
{[0.0224]} \\
\end{array}$ & $\begin{array}{c}0.02 \\
(2008) \\
{[0.0140]} \\
\end{array}$ \\
\hline & Local trough & $\begin{array}{c}0.01 \\
(1897) \\
{[0.0265]}\end{array}$ & $\begin{array}{c}0.02 \\
(1933) \\
{[0.0303]}\end{array}$ & $\begin{array}{c}0.01 \\
(1955) \\
{[0.0289]}\end{array}$ & $\begin{array}{c}0.03 \\
(1984) \\
{[0.0483]}\end{array}$ & $\begin{array}{c}0.02 \\
(2003) \\
{[0.0358]}\end{array}$ & $\begin{array}{c}0.02 \\
(2014) \\
{[0.0345]}\end{array}$ \\
\hline & Change & & -59.84 & 171.31 & 62.71 & $-61.92 *$ & -79.56 \\
\hline \multirow{3}{*}{ Prices Shock } & Local peak & $\begin{array}{c}0.05 \\
(1920) \\
{[0.0287]}\end{array}$ & $\begin{array}{c}0.03 \\
(1935) \\
{[0.0080]}\end{array}$ & $\begin{array}{c}0.03 \\
(1959) \\
{[0.0130]}\end{array}$ & $\begin{array}{c}0.05 \\
(1983) \\
{[0.0240]}\end{array}$ & $\begin{array}{c}0.05 \\
(1990) \\
{[0.0278]}\end{array}$ & $\begin{array}{c}0.03 \\
(2012) \\
{[0.0103]}\end{array}$ \\
\hline & Local trough & $\begin{array}{c}0.01 \\
(1899) \\
{[0.0268]}\end{array}$ & $\begin{array}{c}0.02 \\
(1942) \\
{[0.0353]}\end{array}$ & $\begin{array}{c}0.01 \\
(1953) \\
{[0.0328]}\end{array}$ & $\begin{array}{c}0.02 \\
(1971) \\
{[0.0444]}\end{array}$ & $\begin{array}{c}0.02 \\
(2008) \\
{[0.0411]}\end{array}$ & $\begin{array}{c}0.02 \\
(2008) \\
{[0.0411]}\end{array}$ \\
\hline & Change & & -68.43 & 62.98 & 39.95 & 12.18 & -79.74 \\
\hline \multirow{3}{*}{ Money Shock } & Local peak & $\begin{array}{c}0.04 \\
(1921) \\
{[0.0160]}\end{array}$ & $\begin{array}{c}0.04 \\
(1941) \\
{[0.0168]}\end{array}$ & $\begin{array}{c}0.04 \\
(1971) \\
{[0.0341]}\end{array}$ & $\begin{array}{c}0.04 \\
(1976) \\
{[0.0390]}\end{array}$ & $\begin{array}{c}0.04 \\
(1986) \\
{[0.0309]}\end{array}$ & $\begin{array}{c}0.03 \\
(2008) \\
{[0.0201]}\end{array}$ \\
\hline & Local trough & $\begin{array}{c}0.03 \\
(1894) \\
{[0.0528]}\end{array}$ & $\begin{array}{c}0.03 \\
(1935) \\
{[0.0535]}\end{array}$ & $\begin{array}{c}0.02 \\
(1962) \\
{[0.0470]}\end{array}$ & $\begin{array}{c}0.03 \\
(1984) \\
{[0.0572]}\end{array}$ & $\begin{array}{c}0.02 \\
(2002) \\
{[0.0395]}\end{array}$ & $\begin{array}{c}0.02 \\
(2016) \\
{[0.0420]}\end{array}$ \\
\hline & Change & & -12.41 & 103.58 & -17.22 & -3.67 & -35.26 \\
\hline \multirow{3}{*}{$\begin{array}{l}\text { Transitory } \\
\text { Shock }\end{array}$} & Local peak & $\begin{array}{c}0.06 \\
(1920) \\
{[0.0534]}\end{array}$ & $\begin{array}{c}0.05 \\
(1930) \\
{[0.0404]}\end{array}$ & $\begin{array}{c}0.06 \\
(1952) \\
{[0.0448]}\end{array}$ & $\begin{array}{c}0.05 \\
(1975) \\
{[0.0428]}\end{array}$ & $\begin{array}{c}0.05 \\
(1986) \\
{[0.0387]}\end{array}$ & $\begin{array}{c}0.04 \\
(2008) \\
{[0.0305]}\end{array}$ \\
\hline & Local trough & $\begin{array}{c}0.04 \\
(1865) \\
{[0.0528]}\end{array}$ & $\begin{array}{c}0.04 \\
(1935) \\
{[0.0535]}\end{array}$ & $\begin{array}{c}0.04 \\
(1961) \\
{[0.0470]}\end{array}$ & $\begin{array}{c}0.04 \\
(1984) \\
{[0.0572]}\end{array}$ & $\begin{array}{c}0.02 \\
(1999) \\
{[0.0395]}\end{array}$ & $\begin{array}{c}0.03 \\
(2016) \\
{[0.0420]}\end{array}$ \\
\hline & Change & & -54.69 & 104.78 & -54.87 & $214.10^{*}$ & -48.51 \\
\hline \multirow{3}{*}{$\begin{array}{l}\text { Unconditional } \\
\text { Volatility }\end{array}$} & Local peak & $\begin{array}{c}0.09 \\
(1894) \\
{[0.0896]}\end{array}$ & $\begin{array}{c}0.04 \\
(1940) \\
{[0.0409]}\end{array}$ & $\begin{array}{c}0.05 \\
(1971) \\
{[0.0469]}\end{array}$ & $\begin{array}{c}0.05 \\
(1984) \\
{[0.0493]}\end{array}$ & $\begin{array}{c}0.06 \\
(2008) \\
{[0.0561]}\end{array}$ & $\begin{array}{c}0.06 \\
(2016) \\
{[0.0584]}\end{array}$ \\
\hline & Local trough & $\begin{array}{c}0.04 \\
(1926) \\
{[0.0393]}\end{array}$ & $\begin{array}{c}0.04 \\
(1930) \\
{[0.0896]}\end{array}$ & $\begin{array}{c}0.04 \\
(1945) \\
{[0.0896]}\end{array}$ & $\begin{array}{c}0.05 \\
(1971) \\
{[0.0896]}\end{array}$ & $\begin{array}{c}0.05 \\
(1985) \\
{[0.0831]}\end{array}$ & $\begin{array}{c}0.06 \\
(2008) \\
{[0.0896]}\end{array}$ \\
\hline & Change & & $-98.16^{*}$ & 624.31 & -64.53 & 188.90 & -66.95 \\
\hline
\end{tabular}

Notes: Change are in percentages. Negative values denote reductions in volatility. Local peaks/troughs are extrema values of standard deviation for the sub-sample with the year of the extrema reported in parenthesis and the corresponding lowest value of the peak/ highest value of the local trough from the $16^{\text {th }}-84^{\text {th }}$ percentiles of the distribution in brackets. Statistically significant changes are denoted with an asterisk. 
$\underline{\text { Appendix D: Structural Breaks }}$

\begin{tabular}{|c|c|c|c|c|c|}
\hline \multicolumn{6}{|c|}{ Table D1: Bai-Perron Multiple Break test results } \\
\hline & Breaks & $\begin{array}{c}\text { Scaled } \\
\text { F-statistic }\end{array}$ & $\begin{array}{l}\text { Weighted } \\
\text { F-statistic }\end{array}$ & $\begin{array}{c}\text { Scaled } \\
\text { F-statistic }\end{array}$ & $\begin{array}{l}\text { Weighted } \\
\text { F-statistic }\end{array}$ \\
\hline & & \multicolumn{2}{|c|}{ U.S. } & \multicolumn{2}{|c|}{ U.K. } \\
\hline \multirow{5}{*}{ Real GDP } & 1 & $14.44 *$ & $14.44^{*}$ & 9.51 & 9.51 \\
\hline & 2 & $13.68^{*}$ & $16.10^{*}$ & 8.59 & 10.11 \\
\hline & 3 & $9.81 *$ & $13.46^{*}$ & 6.35 & 8.72 \\
\hline & 4 & $7.56^{*}$ & $12.06^{*}$ & 5.36 & 8.55 \\
\hline & 5 & $6.09 *$ & $11.94 *$ & 4.62 & 9.06 \\
\hline \multirow{5}{*}{ CPI } & 1 & $12.26^{*}$ & $12.26^{*}$ & $12.45^{*}$ & $12.45^{*}$ \\
\hline & 2 & 9.20 & 10.82 & 7.80 & 9.17 \\
\hline & 3 & $9.28^{*}$ & $12.73 *$ & 5.68 & 7.79 \\
\hline & 4 & $8.24 *$ & $13.14^{*}$ & 4.47 & 7.13 \\
\hline & 5 & $6.98^{*}$ & $13.68 *$ & 3.52 & 6.91 \\
\hline \multirow{5}{*}{ Interest rate } & 1 & $17.06^{*}$ & $17.06^{*}$ & $22.42 *$ & $22.42 *$ \\
\hline & 2 & 9.48 & 11.15 & $13.85^{*}$ & $16.29 *$ \\
\hline & 3 & 6.86 & 9.41 & $11.96^{*}$ & $16.41 *$ \\
\hline & 4 & 5.21 & 8.32 & $9.58^{*}$ & $15.29 *$ \\
\hline & 5 & 4.23 & 8.30 & 5.78 & 11.33 \\
\hline \multirow{5}{*}{ Real house prices } & 1 & $13.86^{*}$ & $13.86^{*}$ & $31.01 *$ & $31.01 *$ \\
\hline & 2 & 8.78 & 10.33 & $17.88^{*}$ & $21.04 *$ \\
\hline & 3 & 7.01 & 9.62 & $13.29 *$ & $18.24 *$ \\
\hline & 4 & 5.60 & 8.94 & $10.18^{*}$ & $16.24 *$ \\
\hline & 5 & 4.42 & 8.67 & $7.76^{*}$ & $15.22 *$ \\
\hline
\end{tabular}

Note: $*$ denotes significant values at the $5 \%$ level of significance that reject the null hypothesis of no structural break versus the alternative of the existence of a prespecified number of breaks.

\section{Appendix References}

Canova F. and Gambetti, L. (2010). Do expectations matter? The great moderation revisited. American Economic Journal: Macroeconomics, 2 (3), 183-205.

Carter, C. and Kohn, R. (1994). On Gibbs sampling for state space models. Biometrika, 81 (3), 541-553.

Cogley, T. and Sargent, T. (2005). Drifts and volatilities: monetary policies and outcomes in the post WWII US. Review of Economic Dynamics, 8 (2), 262-302.

Gelman A., Carlin J. B., Stern H. S and Rubin D. B. (1995) Bayesian Data Analysis, Chapman and Hall, London.

Jacquier, E., Polson, N. and Rossi, P. (2004). Bayesian analysis of stochastic volatility models with fat-tails and correlated errors. Journal of Econometrics, 122 (1), 185-212. 